\title{
Hydroide Storage Vessel Wall Stress Measurements
}

by

E. A. Clark

Westinghouse Savannah River Company

Savannah River Site

Aiken, South Carolina 29808

M. J. Pechersky

This paper was prepared in connection with work done under the above contract number with the U.S. Department of Energy. By acceptance of this paper, the publisher and/or recipient acknowledges the U.S. Government's right to retain a nonexclusive, royalty-free license in and to any copyright covering this paper, along with the right to reproduce and to authorize others to reproduce all or part of the copyrighted paper. 


\section{DISCLAIMER}

This report was prepared as an account of work sponsored by an agency of the United States Government. Neither the United States Government nor any agency thereof, nor any of their employees, makes any warranty, express or implied, or assumes any legal liability or responsibility for the accuracy, completeness, or usefulness of any information, apparatus, product, or process disclosed, or represents that its use would not infringe privately owned rights. Reference herein to any specific commercial product, process, or service by trade name, trademark, manufacturer, or otherwise does not necessarily constitute or imply its endorsement, recommendation, or favoring by the United States Government or any agency thereof. The views and opinions of authors expressed herein do not necessarily state or reflect those of the United States Government or any agency thereof.

This report has been reproduced directly from the best available copy.

Available to DOE and DOE contractors from the Office of Scientific and Technical Information, P.O. Box 62, Oak Ridge, TN 37831; prices available from (615) 576-8401.

Available to the public from the National Technical Information Service, U.S. Department of Commerce, 5285 Port Royal Road, Springfield, VA 22161. 


\section{DISCLAIMER}

Portions of this document may be illegible electronic image products. Images are produced from the best available original document. 
WSRC-TR-97-0187

\title{
SMTD
}

STRATEGIC MATERIALS TECHNOLOGY DEPARTMENT

Keywords: Tritium, Hydride Storage Bed, Titanium, Holographic interferometry

Retention - Permanent

\section{Hydride Storage Vessel (HSV) Wall Stress Measurements (U)}

\author{
by \\ Elliot A. Clark and Martin J. Pechersky \\ July 31, 1997

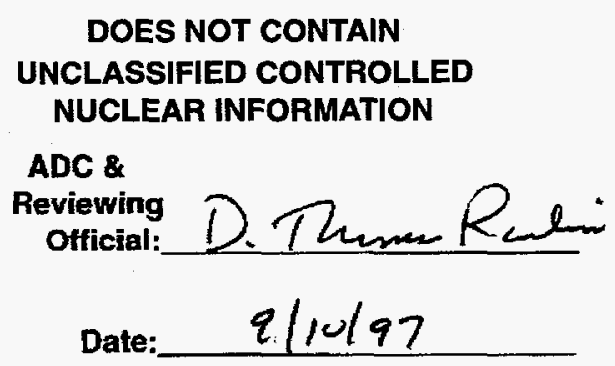

SRTC SAVANNAH RIVER TECHNOLOGY CENTER, AIKEN, SC 29808

Westinghouse Savannah River Company

Prepared for the U. S. Department of Energy under Contracts DE-AC09-

$89 S R 18035$ and DE-AC09-96SR18500 
WSRC-TR-97-0187

APPROVALS

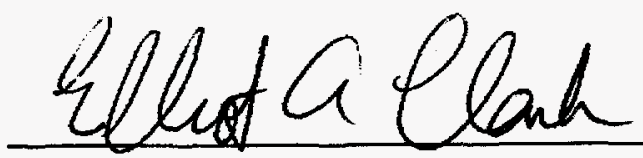

E.A. Clark, AUTHOR
Date:

10 Seplenter 1997

Materials Compatibility and Joining Technology Group

MATERIALS TECHNOLOGY SECTION

Dimeter f Pulluhy

Date: $11 /$ Septembar/1997

Materials Compatibility and Joining Technology Group

MATERIALS TECHNOLOGY SECTION

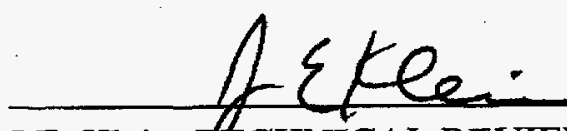

J.E. Klein, ZCHNICAL REVIEWER CHEMICAL AND HYDROGEN TECHNOLOGY SECTION

D. Thumnamin: Date: $9 / 10 / 97$

D.T. Rankin, MANAGER

Materials Compatibility and Joining Technology Group

MATERIALS TECHNOLOGY SECTION

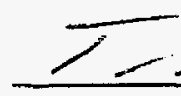

Date: $9 / 10 / 57$

T.L. Capeletti, MANAGER

Date: $9 / 16 / 97$

MATERIALS TECHNOLOGY SECTION

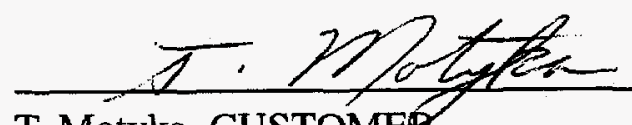

Date: $9 / 10 / 97$

T. Motyka, CUSTOMER

CHEMICAL AND HYDROGEN TECHNOLOGY SECTION

iii 
WSRC-TR-97-0187

THIS PAGE INTENTIONALLY LEFT BLANK 


\section{Contents}

Executive Summary

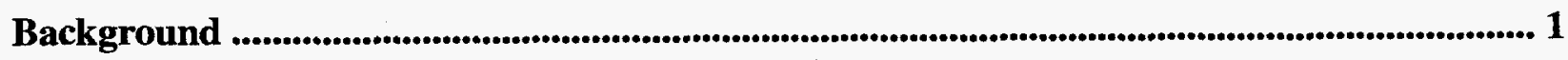

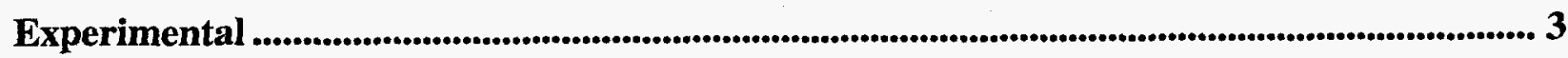

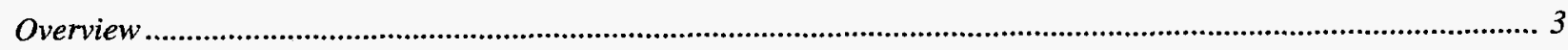

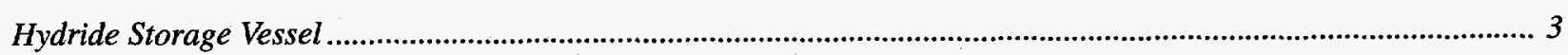

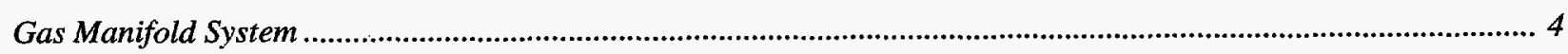

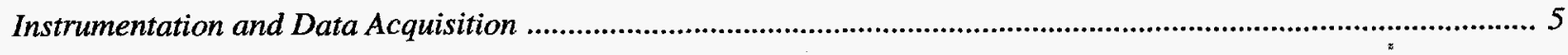

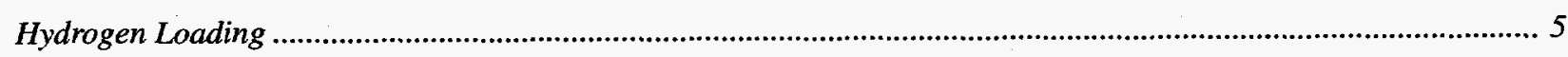

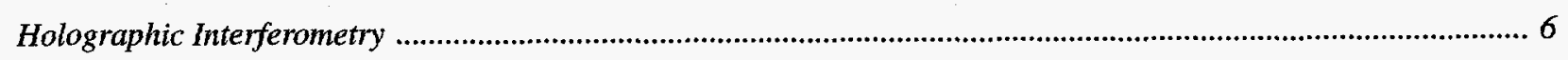

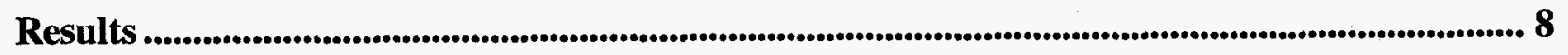

Hydrogen Loading and Hydride Bed Performance ...................................................................................

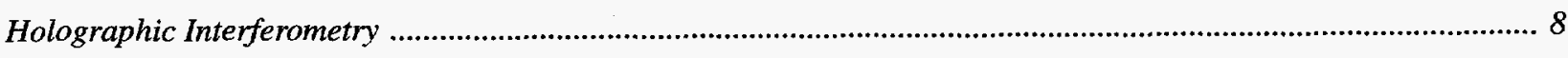

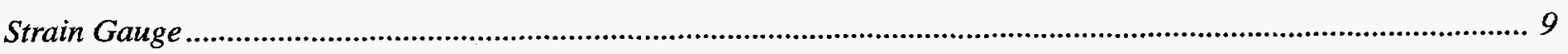

Discussion..$\ldots \ldots \ldots \ldots \ldots \ldots \ldots \ldots \ldots \ldots \ldots \ldots \ldots \ldots \ldots \ldots \ldots \ldots \ldots \ldots \ldots \ldots \ldots \ldots \ldots \ldots \ldots \ldots \ldots \ldots \ldots \ldots \ldots \ldots \ldots \ldots \ldots \ldots \ldots \ldots \ldots \ldots \ldots \ldots \ldots \ldots \ldots \ldots \ldots \ldots \ldots \ldots \ldots \ldots \ldots \ldots \ldots \ldots \ldots \ldots \ldots \ldots \ldots \ldots$

Conclusions

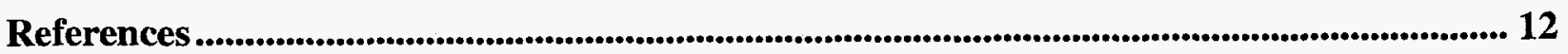

Tables

Figures.$\ldots \ldots \ldots \ldots \ldots \ldots \ldots \ldots \ldots \ldots \ldots \ldots \ldots \ldots \ldots \ldots \ldots \ldots \ldots \ldots \ldots \ldots \ldots \ldots \ldots \ldots \ldots \ldots \ldots \ldots \ldots \ldots \ldots \ldots \ldots \ldots \ldots \ldots \ldots \ldots \ldots \ldots \ldots \ldots \ldots \ldots \ldots \ldots \ldots \ldots \ldots \ldots \ldots \ldots \ldots \ldots \ldots \ldots \ldots \ldots \ldots \ldots \ldots \ldots \ldots \ldots$ 
WSRC-TR-97-0187

Tables

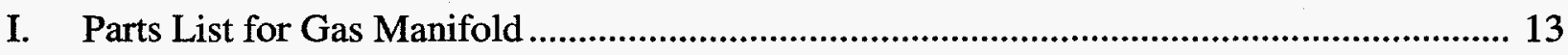

II. Interferogram Fringe Counts from Helium Pressurization .................................................. 14

III. Interferogram Fringe Counts: Reference and after Hydrogen Loading Stages ................... 14 


\section{Figures}

1. Diagram of Hydride Storage Vessel (HSV) ……........................................................ 15

2. Plumbing diagram of gas manifold ………………….................................................... 16

3. System drawing of gas manifold system .................................................................... 17

4. Connection diagram of instrumentation and data acquisition system ................................... 18

5. Calibration factor for hydrogen flow through flow controller, as a function of flow rate ... 19

6. Quantity of hydrogen loaded during each stage, and total loaded during this study ........... 20

7. Schematic diagram of holographic interferometry measurement of radial wall displacement

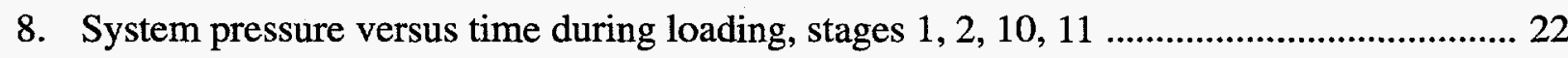

9. Flow rate versus rime for a typical loading (stages 1-10), and for stage 11 ......................... 23

10. Thermowell and surface temperatures versus time during loading stage 2 …..................... 24

11. Maximum thermowell temperature, maximum surface temperature, and thermowell temperature at end of loading for each stage

12. Sequence of interferograms at various helium pressures 26

13. Strain measured by holographic interferometry (Fig. 12), the strain gauge, and that calculated using elasticity theory versus helium pressure in HSV

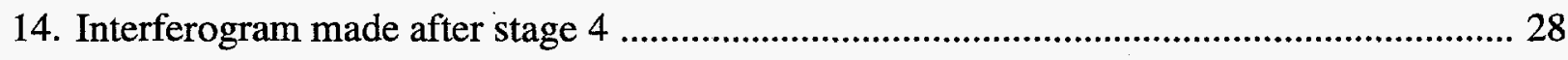

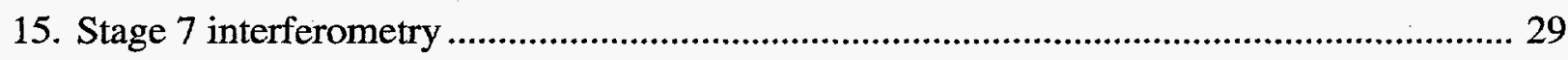

16. Strain after each HSV loading stage, calculated by counting the number of vertical fringes in each interferogram and multiplying by a constant

17. Temperature corrected strain gauge reading before loading, while the HSV was cooling after loading, and after cooling

18. Temperature corrected strain gauge reading as a function of time throughout all hydrogen loading runs 
WSRC-TR-97-0187

\section{Figures (contd)}

19. Radiographs of HSV P-1, revealing partial and full agglomeration during testing before this study

20. Radiographs of HSV P-2, revealing that titanium hydride flows in fully loaded bed ..

21. Photograph of samples of $\mathrm{LaNi}_{4.7} \mathrm{Al}_{0.3}$ (used in process storage beds) and titanium (used in Hydride Storage Vessel) 
WSRC-TR-97-0187

\title{
Hydride Storage Vessel Wall Stress Measurements
}

\author{
Elliot A. Clark and Martin J. Pechersky
}

\section{Executive Summary}

Holographic Interferometry and strain gauge measurements were used to determined whether a prototype Hydride Storage Vessel (HSV) swelled while it was loaded in eleven stages with hydrogen. Bed swelling is inferred from deformation of the surface of the HSV. No swelling was detected, even after saturating the hydride material inside the HSV. The large chunky morphology of the titanium is likely responsible for the lack of wall stress. This morphology also implies that decay helium that remains in the titanium hydride (that is, helium that is not released as gas to the free volume) should not cause significant wall stresses when the HSV is used for long-term tritium storage. Holographic interferometry proved to be an extremely sensitive technique to measure swelling, having a detection limit of about 3 microns surface displacement.

\section{Background}

Hydrogen isotopes are processed and stored in many types of hydride storage beds at the Savannah River Site [1]. Many materials (normally intermetallic compounds or pure metals) react with hydrogen and form metallic hydride compounds. The hydrogen gas can be recovered by heating and decomposing the hydride. Hydride storage beds consist of the combination of hydride forming material, the container for this material and its connections (pipe, valves, etc.) to the remainder of the processing system, and the necessary heating and cooling system to control the absorption and desorption of the hydrogen isotopes. Advantages of solid hydride storage of hydrogen isotopes include safer storage in a smaller volume, and enhanced control of gas flow to and from the bed. Sometimes pumps are not required, so facilities can be simplified.

The Hydride Storage Vessel (HSV) has been designed, manufactured, and is currently being used for long-term tritium storage at the Savannah River Site [2]. The HSV consists of large, irregularly shaped pellets ("chunks") of titanium that are contained in a Type $347 \mathrm{H}$ stainless steel vessel (Fig. 1). The HSV has two gas inlet tubes, both having sintered metal filters at the tube outlet inside the vessel. One tube end is embedded in the titanium, and the other ends in the free space ("free 
board") above the titanium. Normally, hydrogen isotopes are loaded onto the bed through the inlet embedded in the titanium. The other inlet serves as a backup, to allow flow-through processing if required, and to relieve inert gas blanketing if it occurs. The titanium used in the HSV is manufactured using proprietary techniques by the hydride storage material vendor to help ensure hydrogen isotope uptake.

When hydrides form, the metal crystal lattice expands significantly in all materials [3]. An earlier study revealed that measurable stresses can occur in the container at high hydrogen content in a particular hydride bed design [4]. This bed was a prototype of the horizontal hydride storage beds used in the 233-H Replacement Tritium Facility. The intermetallic compound $\mathrm{LaNi}_{4.7} \mathrm{Al}_{0.3}$ is used in 233- $\mathrm{H}$, and the similar compound $\mathrm{LaNi}_{4.25} \mathrm{Al}_{0.75}$ was used in the prototype bed stress experiments. $\mathrm{LaNi}_{4.25} \mathrm{Al}_{0.75}$ becomes a fine powder after initial activation (preparation for use as a hydride storage medium) and cycling. Eighteen strain gauges mounted at eleven locations on the bed surface were employed to measure strain of the wall exterior while the bed was loaded with fixed amounts of hydrogen. The wall stress was negligible until the hydrogen to metal atom ratio (H/M) exceeded 0.5 ; at about $\mathrm{H} / \mathrm{M}=0.7$ the wall strain was significant, and increased to the maximum at the maximum loading of $\mathrm{H} / \mathrm{M}=0.82$. Even though the strain was easily measurable, at no point did the wall stress, calculated from the measured wall strain, exceed the design pressure of the vessel. The study concluded that the $\mathrm{LaNi}_{5-\mathrm{x}} \mathrm{Al}_{\mathrm{x}}(\mathrm{x}=0.3,0.75)$ storage beds are safe.

There has been at least one other study of wall stress during hydriding [5]. In this study, $\mathrm{LaNi}_{5}$ powder was placed in a specially designed cylincrical container which had a force transducer at one end. When hydrogen gas was admitted into the container, the transducer recorded the outward stress caused by expansion when the hydride formed. The variation of transducer stress with hydrogen to metal atom ratio was similar to that found in the prototype SRS hydride bed [4]. In addition, the powder in the container could be pre-stressed, and there was evidence that the amount of hydrogen absorbed at a given pressure was lower when the $\mathrm{LaNi}_{5}$ was pre-stressed before loading with hydrogen.

The study reported here was undertaken to determine whether any stress exists in the HSV walls from hydriding. This vessel is designed to contain large quantities of tritium for extended times. The loaded HSVs are stored outside a tritium confinement system (such as a glove box or air hood), and so safety and reliability are extremely important. Holographic interferometry was employed, along with a strain gauge, to measure surface displacements (surface strain in the case of the strain gauge). Advantages of holographic interferometry for measuring displacement compared to strain 
gauging include the ability to measure surface displacement over large areas, without attaching multiple gauges. Holographic interferometry is also more sensitive than normal strain gauges. Wall stress can be calculated from the measured surface displacement or strain.

\section{Experimental}

\section{Overview}

In this study, a prototype Hydride Storage Vessel was filled with hydrogen in eleven stages using a gas manifold system designed for this purpose. After each stage, the vessel cooled to ambient temperature, dissipating the heat released during the hydriding reaction. Two methods were then used to detect any possible swelling after each stage: holographic interferometry and a strain gauge.

\section{Hydride Storage Vessel}

One of the two prototype Hydride Storage Vessels, HSV-P1, was employed (Fig.1) [2]. Prior tests using this vessel included several cycles of loading, unloading, and flowing gas isotope exchange. The vessel was provided back filled with about 1 atmosphere argon cover gas, after hydrogen and deuterium were almost completely unloaded by heating and evacuation. (A residual content of about 63 standard liter, or $0.06 \mathrm{Q} / \mathrm{M}$ was estimated [7].) The prototype vessels differ from production HSVs in having a thermowell from the top penetrating most of the titanium, which enabled the temperature in the middle of the titanium or titanium hydride to be monitored. When HSV-P1 was inverted, there was no sound of freely flowing titanium. This indicated that the titanium had agglomerated or partially sintered during the previous tests. Radiography subsequently confirmed this (Fig. 20). Agglomeration is sometimes observed after production HSV loading, since the heat given off during the hydriding reaction is substantial. HSV-P1 underwent several complete hydriding cycles (production units are only loaded once), including desorption cycles at about $700 \mathrm{deg}$. C, so agglomeration is expected. The HSV was mounted to the optical table (required for holographic interferometry) using steel tabs welded to the bottom support. In addition, the side of the HSV that was to be illuminated with the laser was painted with a matte white paint at the beginning, to provide a diffusely reflecting surface. 
WSRC-TR-97-0187

\section{Gas Manifold System}

A gas manifold inlet system was designed and fabricated, to control the flow of hydrogen and helium gas into HSV-P1 (Table I, Figs. 2, 3). Helium was used for routine manifold performance testing and to pressurize the vessel at the end of hydrogen loading to verify that the strain gauge and holographic interferometry functioned properly. Both helium and hydrogen came from standard size 1A cylinders, having stated purities of $99.9999 \%(\mathrm{He})$ and $99.999 \%(\mathrm{H})$. Pressure relief valves were installed at the outlet of each gas regulator that would vent to the building hood exhaust at 15 psig. This pressure was chosen because HSV-P1 was not fabricated to be an ASME Code stamped vessel, and thereby is restricted to operating pressures lower than $15 \mathrm{psig}$. The system was evacuated using a mechanical pump, with a trap to prevent pump oil from backstreaming into the system and a check valve to assure flow was outward from the pump in the pump exhaust. The pump was exhausted to the chemical hood exhaust stream in Building 773-A. The stainless steel manifold tubing had two tube sizes: 1/4" and 1/2" OD (Fig. 3). The larger tube size was used where the system would be evacuated to low pressure. Two types of valve were used, one for each tube size. The HSV was attached to the manifold by two flexible stainless steel hoses (Table I), with two valves allowing the larger flexible hose to be disconnected from the small flexible hose and thus also the optical table where the HSV was positioned. Preliminary experiments revealed that room vibrations transferred through the hose affected the contrast of interferograms if the hose remained connected.

The system included a calibrated volume vessel having nominally 1 liter volume. The volume of this vessel and other parts of the gas manifold was measured by attaching a standard calibration volume (MTE No. HTS001223, volume $3787.6 \mathrm{cc}$ ) to the system, filling it with helium, and sequentially opening valves to various parts of the system and recording the pressure after each valve opening. The manifold calibrated volume vessel was found to have a volume of $1.04 \pm 0.01$ liter. This volume was used to calibrate the flow controller (below). Manifold system pressure was monitored by a pressure transducer at pressures greater than about 2.5 Torr or by a thermocouple vacuum gauge at pressures down to $\sim 10^{-2}$ Torr (during evacuation). Operation of the pressure transducer was verified by measuring the pressure of the room atmosphere, and the transducer was zeroed when the thermocouple vacuum gauge indicated the system pressure was much less than 1 Torr.

Hydrogen flow was controlled by a mass flow controller/readout device, that could measure and limit flow to a set value for flow rates of up to $10 \mathrm{liter} / \mathrm{min}$. The flow controller was verified to operate correctly after the manifold system volumes were measured (above) by comparing the 
instantaneous and integrated flow of hydrogen into the measured volumes as measured by the flow controller with that determined by the pressure (measured by the transducer) and volume the gas flows into, assuming constant temperature. A correction factor that increased with decreasing flow rate was necessary for hydrogen at flow rates less than $4 \mathrm{liter} / \mathrm{min}$ (Fig. 5). The hydrogen pressure at the inlet of the flow controller was always set to 10 psig using the cylinder regulator.

\section{Instrumentation and Data Acquisition}

Three Type K thermocouples were located inside the HSV thermowell, on its surface, and in the room air. They were attached to special thermocouple input modules in the data acquisition system. All three thermocouples were verified to operate correctly by measuring the temperature of an ice water bath and boiling water at the end of experiments.

The high temperature strain gauge (Table I) was mounted on the side of the HSV away from the laser illumination, at the mid point of the container, to measure strain in the circumferential ("hoop") stress direction. The readout instrument was used in the "quarter bridge" mode. The gain of the strain gauge readout was readjusted before each visual reading by internal calibration in the readout instrument. The zero point of the readout was set to zero before the initial loading and was not changed during the entire set of experiments. The zero of the readout meter was adjusted as needed, using a setting provided for this purpose on the readout instrument. All strain gauge readings reported here were corrected using the published temperature correction factor curve for the gauge model used, and the measured surface thermocouple temperature.

A computer and modular data acquisition system were used to record the output of the manifold pressure instruments (both transducer and thermocouple vacuum gauge), the strain gauge readout, and the mass flow controller readout (Fig. 4), and the three thermocouples. "LabView" software was used to control data acquisition and store data. The strain gauge data used for data analysis was read from the panel of the instrument and recorded in the laboratory notebook (Table I); the data recorded in the computer data files was only used for monitoring because of excessive electrical noise.

\section{Hydrogen Loading}

During all loading stages hydrogen was loaded at $5 \mathrm{liter} / \mathrm{min}$, in the range where the flow controller read directly the amount of hydrogen flowing without correction (see above). The amount of hydrogen was calculated by numerically integrating the flow rate with respect to time data. The 
WSRC-TR-97-0187

first hydrogen loading stage was nominally 100 liters (STP), stages 2 through 10 were nominally 200 liters, and the last stage (11) was about 58 liters (Fig. 6). Loading ceased during stage 11 when the bed became saturated. A total of 1961 liters hydrogen was loaded, which corresponds to a hydrogen to metal atom ratio (H/M) of about 1.91 (assuming 4399 grams titanium, $47.90 \mathrm{gram} /$ mol) [7]. The HSV was pressurized in stages with helium after the HSV was completely loaded with hydrogen, to verify that both the strain gauge and holographic interferometry were able to measure vessel swelling (discussed below).

\section{Holographic Interferometry}

Holographic interferometry was the primary method used to determine the wall strain, and strain gauge measurement of circumferential strain was the confirmatory method. The main advantage of holographic interferometry is the ability to determine strain over a large area with a single measurement. The holographic method used in this study is known as real time holography (Fig. 7). In this technique, a hologram of the HSV is created by simultaneously illuminating the HSV with the object beam, and the holographic plate with the reference beam. Light in both beams comes from the same laser source. The exposure time is about $0.1 \mathrm{~s}$. Some of the light reflected from the HSV hits the holographic plate. A complex interference pattern between this scattered light and the light from the reference beam is recorded on the plate. When the plate is developed, a virtual image of the HSV can be seen when the reference beam illuminates the plate. This virtual image is viewed by looking through the holographic plate in the direction of the HSV. This image is the "hologram" of the HSV and it contains a record of the exact location of the surfaces of the HSV relative to the holographic plate at the time of exposure. Hydrogen gas is then added to the HSV. After the HSV has cooled (so that only permanent displacements are observed, not temperature effects), both the reference beam and the object beam are used to illuminate the HSV. The hologram and the real HSV are viewed simultaneously through the holographic plate. Any change in location of the HSV surface is indicated by a fringe pattern which is superimposed on the shape of the HSV. Ideally, if there has been no change in the shape or location of the HSV, the virtual image and the scattered light from the HSV will destructively interfere at all locations on the plate and no image will be seen. (Complete interference occurs only if both the phase and the brightness of the hologram and the light scattered from the HSV are the same.) If there has been any change in position of the HSV surface from its original position as recorded in the virtual image, then fringes will be observed. This fringe pattern superimposed on the shape of the object is known as a "holographic interferogram". 
Changes in position of the surface are caused by either rigid body displacements or strain. Rigid body displacements can result from translating, rotating, or tilting the HSV, and are unimportant for HSV performance studies. On the other hand, surface deformation and strain of the HSV may be an indication of hydride bed swelling, and this is the property to be measured in this study. The sensitivity of the interferometer is given by:

$$
z=(m \cdot \lambda / 2) / \cos ^{2}(\psi / 2)
$$

where

$$
\begin{aligned}
& z=\quad \text { displacement in the direction of the interferometer. } \\
& m=\quad \text { fringe order of the dark fringes }=0,1,2, \ldots \\
& \lambda=\quad \text { wavelength of the laser light }=0.5145 \mu \mathrm{m} \\
& \psi=\quad \begin{array}{l}
\text { the angle formed by the object beam as it illuminates the } \\
\text { HSV and then scattered from the HSV to the holographic } \\
\text { plate (Fig. } 7) . \text { This angle defines the direction of surface } \\
\text { displacement to which the interferometer is sensitive. }
\end{array}
\end{aligned}
$$

In this case the angle $y$ was sufficiently small $\left(\sim 5^{\circ}\right)$, so that the measured displacement is along a line normal to the holographic plate and the HSV. Near the center of the HSV, $z$ is the radial displacement and at the edges of the HSV only rigid body displacements will be observed. The surface strain as measured near the center of the HSV is simply $z / R$ where $R$ is the outer radius of the HSV.

In the current study, the holograms were recorded on a commercially available reusable holographic plate. After the hydrogen was loaded and the temperature stabilized over night, the interference pattern created by the hologram taken before loading and the live image was observed on the holographic plate and these interferograms were imaged onto a video camera and stored on a computer for later analysis. 
WSRC-TR-97-0187

\section{Results}

\section{Hydrogen Loading and Hydride Bed Performance}

After evacuating the argon cover gas, hydrogen was immediately absorbed by HSV-P1 during the first loading stage (Fig. 8). During stages 1 through 10, the system pressure remained at between 100 and 130 Torr during loading (Fig. 8) until the pressure exhibited anomalies at the end of loading 10 that indicated the titanium hydride was nearly saturated (for the loading conditions used in this experiment). During stage 11, the system pressure rose to the level set by the hydrogen regulator (Fig. 8), 1200 Torr, and the flow concomitantly decreased and then stopped (Fig. 9).

The temperature inside the bed and at the vessel surface rose significantly during loading (Fig. 10), caused by the heat of formation of titanium hydride. The maximum temperatures observed at the thermowell and surface varied with each loading stage (Fig. 11), presumably reflecting both the expansion of the region of hydride formation as more hydrogen is absorbed, and cooling of already-formed hydride by flowing hydrogen. In this scenario of bed behavior, hydrogen flowing into the titanium forms hydride as soon as it contacts unreacted titanium, so as the bed is sequentially loaded, the hydriding reaction occurs in a region that is further and further away from the inlet filter. This continues until the bed becomes full.

\section{Holographic Interferometry}

Holographic interferograms taken at each pressure level during helium pressurization clearly reveal the sensitivity of holographic interferometry to surface displacement (Fig. 12). The fringes in the holographic interferograms can be viewed as contour lines of equal surface displacement (component in the direction of the holographic camera), and the slight swelling by pressurizing is easily observed. The circumferential strain can be calculated from the number of fringes and the laser wavelength, and the strain measured during helium pressurization agrees well with the strain expected from the given pressurization (Fig. 13, Table II).

The appearance of interferograms taken after hydrogen loadings varied. The interferograms can be divided into three general groups: horizontal (often curved) fringes (stages 3, 4, 9, 10, 11) (Fig. 14), vertical fringes (stages $1,5,6,7$ ) (Fig. 15c), and no fringes (stages 2, 8). Horizontal fringes likely represent rigid body tilting of the HSV, and vertical fringes may represent wall displacement. By counting the number of vertical fringes that cut a hypothetical horizontal line in the middle of the HSV, the wall strain can be calculated. When this procedure is performed on the helium pressurization interferograms, there is excellent agreement between the surface displacement measured by interferometry and that predicted by elasticity theory (Table II, Fig. 13). When the procedure is 
applied to the vertical fringes of HSV loadings, an irregular pattern of strain versus loading is observed (Table III, Fig. 16).

After each loading stage ended, about 18 hours were required for the HSV to cool to room temperature (Fig. 10). Since temperature changes and gradients significantly expand and contract materials, neither interferograms nor strain gauge readings were made for wall stress analysis until after at least this amount of time. Interferogram and strain readings reflect thermal expansion, not possible stress from hydride expansion, if taken sooner. Interferograms made before the HSV cooled have complex patterns (Fig. 15 b). When the HSV cools, the complex patterns disappear (Fig. 15 c).

\section{Strain Gauge}

No systematic change of strain gauge reading with increasing bed loading was observed (Fig. 17). The only pattern observed was the tendency of the strain gauge readings made during cooling to be similar. The helium pressurization test revealed that the strain gauge functioned fairly well over a small range of time and strain (Fig. 13). Plotting the measured strain for all stages with time reveals a quasi-cyclic pattern that could indicate the strain gauge measurements were influenced by unknown environmental factors (Fig. 18). The long-term stability of either the strain gauge or the strain readout device was insufficient to monitor HSV wall strain for more than a few hours.

\section{Discussion}

Soft polycrystalline alloys are normally considered to yield at either $0.1 \%$ or $0.2 \%$ strain (offset), which is 1000 or 2000 micro strain [6]. The cumulative strain from vertical fringes, 77 micro strain (Table III, Fig. 16), is much lower than this. The strain gauge revealed no consistent change of strain with hydrogen loading (above), and the maximum strain reading was 166. Taken together, these results from both holographic interferometry and the strain gauge are consistent with no stress in the HSV wall when fully loaded with hydrogen.

Other evidence that the wall stress is low is found in radiographs of loaded HSVs. When the HSV is inverted much of the titanium flows from the bottom to the top. Some titanium agglomerates at the inlet filter in some HSVs, probably occurring by partial sintering from the heating resulting from the initial hydride reaction near the inlet filter (Fig. 19), and from heating before loading to activate the bed (preparing it to absorb hydrogen). Prototype HSV-P2 (the other prototype, not used for this work) was radiographed after having been fully loaded, showing that the titanium hydride powder flows when it was inverted (Fig. 20). 
The lack of wall stress in the HSV, compared to the earlier studies of hydride bed swelling [4,5], is likely related to the morphology of the hydride material. $\mathrm{LaNi}_{5-\mathrm{x}} \mathrm{Al}_{\mathrm{x}}(\mathrm{x}=0,0.3,0.75)$ is commonly a fine powder, especially after being exposed to several cycles of hydrogen loading and unloading (Fig. 21). The powder grains are in intimate contact and exert force on neighboring grains when they expand upon hydride formation. Friction between the fine powder may also play a role [5]. The powder does not expand into any free void space in the container. The titanium used in the HSV has the form of large chunks, with significant void space around each chunk (Fig. 21). When the titanium expands, most of the time the hydride does not contact neighboring titanium hydride and so no force occurs between neighboring particle and the container is not exposed to stress. When the solute helium- 3 concentration increases in HSVs used for tritium storage, caused by tritium radioactive decay, it is believed that the stress in the wall will be similarly low for the same reason: the open, blocky morphology of the titanium hydride chunks.

Holographic interferometry is a very sensitive method to measure displacement or strain. In the current study, many of the fringes observed in interferograms ("horizontal" fringes) occurred because of minute tilting of the HSV during testing. For example, 17 horizontal fringes in this study correspond to a tilt of about 3 arc seconds, or about $10^{-3}$ degree; this is about $4.4 \mu \mathrm{m}$ movement of the top with respect to the bottom. If there is a large displacement of the HSV between the time the hologram was made and the time the interferogram was made, no fringes are observable. No fringes were observed only after stages 2 and 8 , indicating that although the method is very sensitive, it is also robust and useful when the proper experimental precautions are taken. Examples of proper precautions are securely anchoring the bottom to the optical bench, and decoupling the manifold when holograms or interferograms are made. 
WSRC-TR-97-0187

\section{Conclusions}

Holographic interferometry and a strain gauge were used to monitor possible strain in the wall of a prototype Hydride Storage Vessel (HSV) during loading with hydrogen in stages up to full loading. The following conclusions were drawn from results of this study.

1. No consistent indication of wall stress was observed at any time during loading with hydrogen, even up to the maximum loading.

2. The chunky morphology of the titanium storage material is probably responsible for the lack of wall stress upon hydriding. Decay helium-3 creation during long-term storage will probably not cause wall stresses in the HSV, for the same reason.

3. Holographic interferometry is a highly sensitive method of detecting small surface displacements and strain.

\section{Acknowledgments}

Support from the following people and organizations is gratefully acknowledged: J. Klein (Chemical and Hydrogen Technology - overall project and technical support), K. Meeler (Engineered Equipment Section drawing group - manifold drawing), D. Trapp (Engineered Equipment Section High Pressure Lab - manifold construction), J. Mitrik (manifold design and procurement), S. Collins (Engineered Equipment Section - computer data acquisition system), S. Hatcher (procurement and facilities management), D. Williams (attaching strain gauge). 
WSRC-TR-97-0187

\section{References.}

1. M.S. Ortman, L.K. Heung, A. Nobile, R.L. Rabun, III. "Tritium Processing at the Savannah River Site: Present and Future”. J. Vac. Sci. Technol A, Vol. 8, No. 3, pp 2881-2889 (MayJune 1990).

2. L.K. Heung. "Titanium for Long Term Tritium Storage". Report WSRC-TR-94-0596, Westinghouse Savannah River Co., Savannah River Site, Aiken, SC 29808, (December 1994).

3. H. Peisl. "Lattice Strain due to Hydrogen in Metals", in Hydrogen in Metals I: Basic Properties, Topics in Applied Physics Vol. 28, Ed. G Alefeld and J. Voelkl, Springer-Verlag, pp 53-74 (1978).

4. S.T. McKillip, C.E. Bannister, and E.A. Clark. "Stress Analysis of Hydride Bed Vessels Used For Tritium Storage". Fusion Technology, Vol. 21, No. 2 part 2, pp 1011-1016 (March 1992).

5. M. Kawamura, S. Ono, and Y. Mizuno. "Stress Induced in Metal Hydrogen Powder Bed by Hydriding Reaction". Proceedings of International Symposium on Metal-Hydrogen Systems, Miami, Florida USA, pp 489-500 (1981.).

6. G.E. Dieter. Mechanical Metallurgy, Second Edition. McGraw-Hill, New York, p 332 (1976).

7. J.E. Klein, Westinghouse Savannah River Co. Private communication. 


\begin{tabular}{|l|l|c|}
\hline Component & Product Name and Model Number & $\begin{array}{c}\text { Key in } \\
\text { Fig. 3 }\end{array}$ \\
\hline Pressure Transducer & MKS 220 (0-2500 Torr) & 15 \\
\hline Pressure Readout & MKS PDR-5B & 4 \\
\hline Flow Controller & MKS Type 1259C - 10000 sccm & 18 \\
\hline Flow Controller Readout & MKS Type 246 & 2 \\
\hline Thermocouple Vacuum Gauge & MDC TGT 2A, Model \#511013 & 17 \\
\hline Thermocouple Vacuum Readout & MDC CT, Model \#510009 & 1 \\
\hline Mechanical Pump & Edwards High Vacuum Pump E2M-1 & 13 \\
\hline Oil Trap for Mechanical Pump & $\begin{array}{l}\text { Approx Body 5"OD by 5"Tall by 3" Ends w/3.5" OD } \\
\text { \& 11" Total Length }\end{array}$ & 14 \\
\hline Whitey Ball Valves & Whitey Valve SS-43S4 (1/4" section of manifold) & 5 \\
\hline Nupro Valves & $\begin{array}{l}\text { Nupro Valve SS-8BK (1/2" section of manifold, and } \\
\text { flexible hose) }\end{array}$ & 6 \\
\hline Calibrated Volume & Whitey 1000 cc nominal (1.04 liter measured) & 16 \\
\hline Flexible Metal Hose & $\begin{array}{l}\text { Swagelok Model SS-H08 SL8-168 (14 foot, 1/2" ID } \\
\text { nominal) }\end{array}$ & 23 \\
\hline Computer & Macintosh II & 19 \\
\hline Tubing & $\begin{array}{l}\text { Type 304 stainless steel, 1/2" and 1/4" OD, 0.035" wall } \\
\text { thickness }\end{array}$ & 20,21, \\
\hline Strain Gauge Readout & Vishay-Allis Model 20 & 22 \\
\hline Strain Gauge & $\begin{array}{l}\text { Micro-M easurements WK-09-250BG-350, M-Bond 600 } \\
\text { high temperature epoxy }\end{array}$ & $\mathrm{n} / \mathrm{a}$ \\
\hline $\begin{array}{l}\text { Thermowell, Room } \\
\text { Thermocouples }\end{array}$ & Omega M odel TJ36-CASS-116U-12, Type K & $\mathrm{n} / \mathrm{a}$ \\
\hline Surface Thermocouple & Omega Model 88101-K-TT, Type K & $\mathrm{n} / \mathrm{a}$ \\
\hline Aluminum Panel & Bud \# PA-1103 & 3 \\
\hline $1 / 2 "$ to 1/4" Reducing Union & Swagelok \#SS-810-6-4 & 7 \\
\hline $1 / 4 "$ to 1/8"Female Connector & Swagelok \#SS-400-7-2 & 8 \\
\hline $1 / 2 "$ Union Tee & Swagelok \#SS-810-3 & 9 \\
\hline $1 / 4 "$ Union Tee & Swagelok \#SS-400-3 & 10 \\
\hline $1 / 2 "$ Union Elbow & Swagelok \#SS-810-9 & 11 \\
\hline $1 / 2 "$ Check Valve & Nupro \#B-8C-113 & 25 \\
\hline Screw \& Nut & $1 / 4-20$ by 0.375 & 24 \\
\hline Aluminum Angle & $11 / 2 "$ by 2", 8"long & \\
\hline & & 2 \\
\hline
\end{tabular}

Table I. Parts List for Gas Manifold. Key is for Fig. 3. See also Fig. 2. 


\begin{tabular}{|r|c|c|c|}
\hline $\begin{array}{c}\text { Pressure } \\
\text { (Torr) }\end{array}$ & $\begin{array}{c}\text { Horizontal } \\
\text { Fringes }\end{array}$ & $\begin{array}{c}\text { Vertical } \\
\text { Fringes }\end{array}$ & Strain \\
\hline 10 & 0.5 & 0 & 0 \\
\hline 413 & 2 & 3 & 5.1 \\
\hline 740 & 3 & 4 & 6.8 \\
\hline 1290 & 5 & 6 & 10.2 \\
\hline 0 & 1 & 0 & 0 \\
\hline
\end{tabular}

Table II Interferogram Fringe Counts from Helium Pressurization. Strain calculated from vertical fringes. See Fig. 13.

\begin{tabular}{|c|c|c|c|c|c|c|c|c|}
\hline & Reference I & terferogr & $m:$ & After $\mathrm{H} 2 \mathrm{U}$ & take and & temperatures & ble: & \\
\hline $\begin{array}{l}\text { Loading } \\
\text { Stage } \\
\text { No. }\end{array}$ & $\begin{array}{c}\text { Horizontal } \\
\text { Fringes }\end{array}$ & $\begin{array}{l}\text { Vertical } \\
\text { Fringes }\end{array}$ & Note & $\begin{array}{c}\text { Horizontal } \\
\text { Fringes }\end{array}$ & $\begin{array}{l}\text { Vertical } \\
\text { Fringes }\end{array}$ & Note & $\begin{array}{l}\text { Strain } \\
\text { (from } \\
\text { vertical } \\
\text { fringes }\end{array}$ & $\begin{array}{c}\text { Cumulative } \\
\text { Strain }\end{array}$ \\
\hline 1 & 10 & 0 & tilt & 0 & 16 & & 27.2 & 27.2 \\
\hline 2 & $\begin{array}{l}11 \\
28\end{array}$ & $\begin{array}{l}0 \\
0\end{array}$ & $\begin{array}{l}\text { tilt } \\
\text { tilt (after } \\
\text { flex hose } \\
\text { attached) }\end{array}$ & $\overline{0}$ & $\overline{0}$ & poor image & $\overline{0}$ & 27.2 \\
\hline 3 & $\overline{0}$ & $\overline{0}$ & & 17 & 3 & $\begin{array}{l}\text { mainly tilt- } \\
\text { complex }\end{array}$ & 5.1 & 32.3 \\
\hline 4 & & & & 7 & $\overline{2}$ & mainly tilt & 3.4 & 35.7 \\
\hline 5 & 0.5 & 0 & & $\overline{2}$ & 3 & & 5.1 & 40.8 \\
\hline 6 & 0 & $\overline{0}$ & & $\overline{0}$ & $\overline{14}$ & hard to see & 23.8 & 64.6 \\
\hline 7 & 0 & $\overline{0}$ & & 4 & 5 & clear & 8.5 & 73.1 \\
\hline 8 & $\overline{0}$ & $\overline{0}$ & & 0 & 0 & poor image & 0 & 73.1 \\
\hline 9 & 0 & 0.5 & & 5 & 0 & tilt & 0 & 73.1 \\
\hline 10 & 2 & 0 & tilt & 3 & 0 & tiilt & 0 & 73.1 \\
\hline 11 & 0 & $\overline{0}$ & & 1 & $\overline{2}$ & mainly tilt & 3.4 & 76.5 \\
\hline
\end{tabular}

Table III. Interferogram Fringe Counts: Reference and after Hydrogen Loading Stages. Note many horizontal fringes in both reference and loaded interferograms, interpreted as being from rigid body tilting. Strain calculated from vertical fringes as in Table II. Strain graphed in Fig. 16. 
WSRC-TR-97-0187

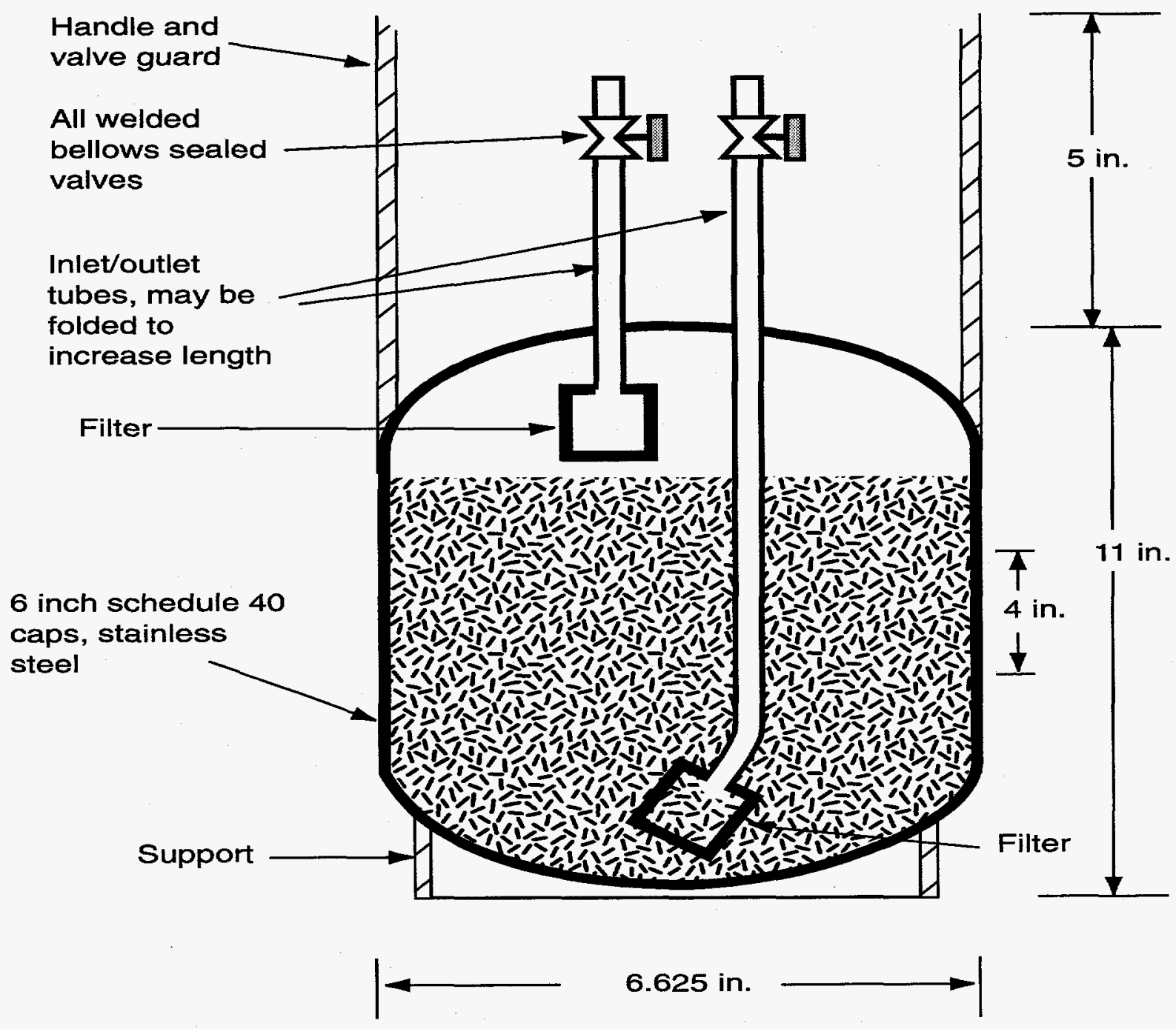

Figure 1. Diagram of Hydride Storage Vessel (HSV) 
WSRC-TR-97-0187

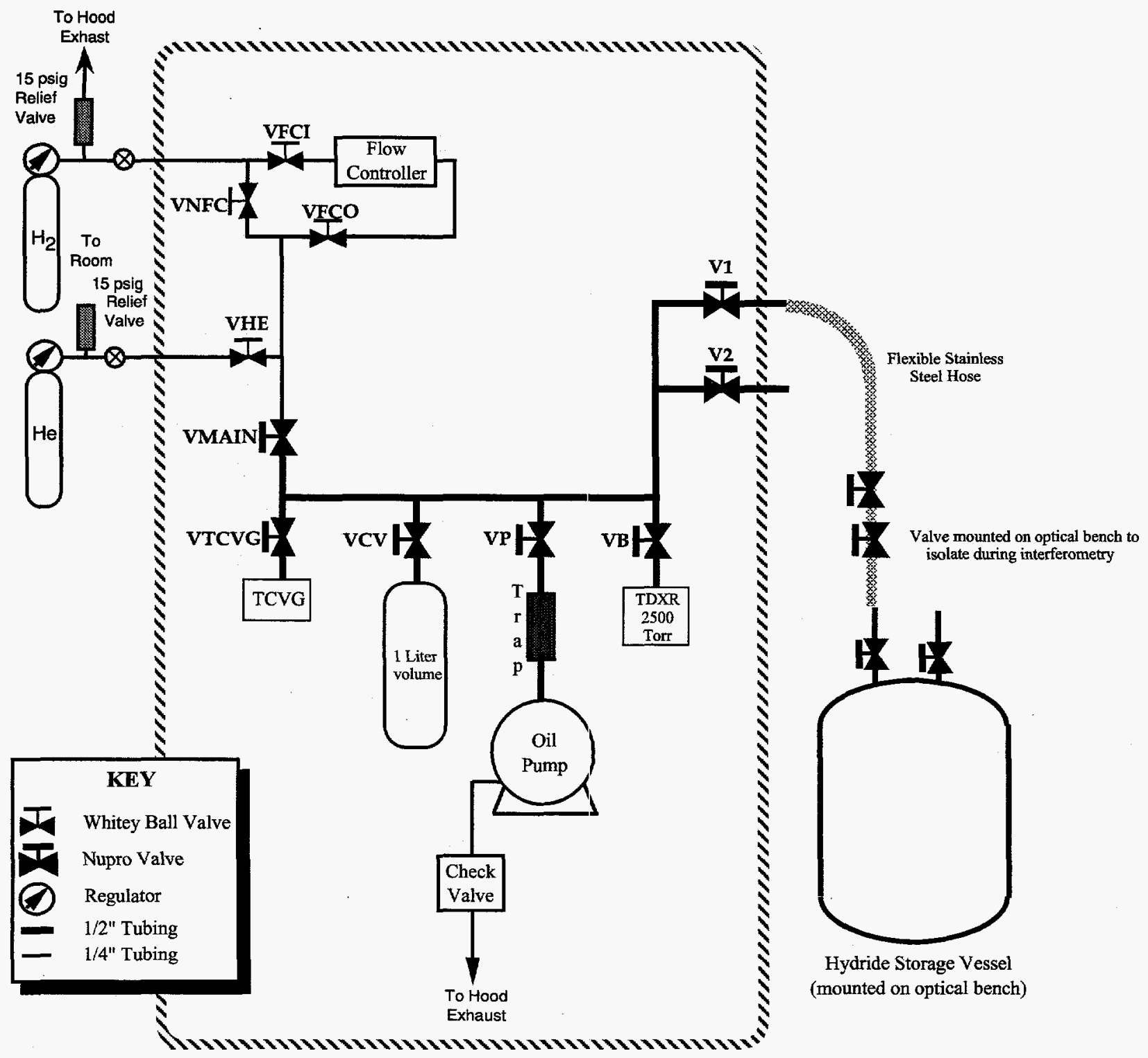

Figure 2. Plumbing diagram of gas manifold. See also Figure 3. Parts are listed in Table I. 
WSRC-TR-97-0187

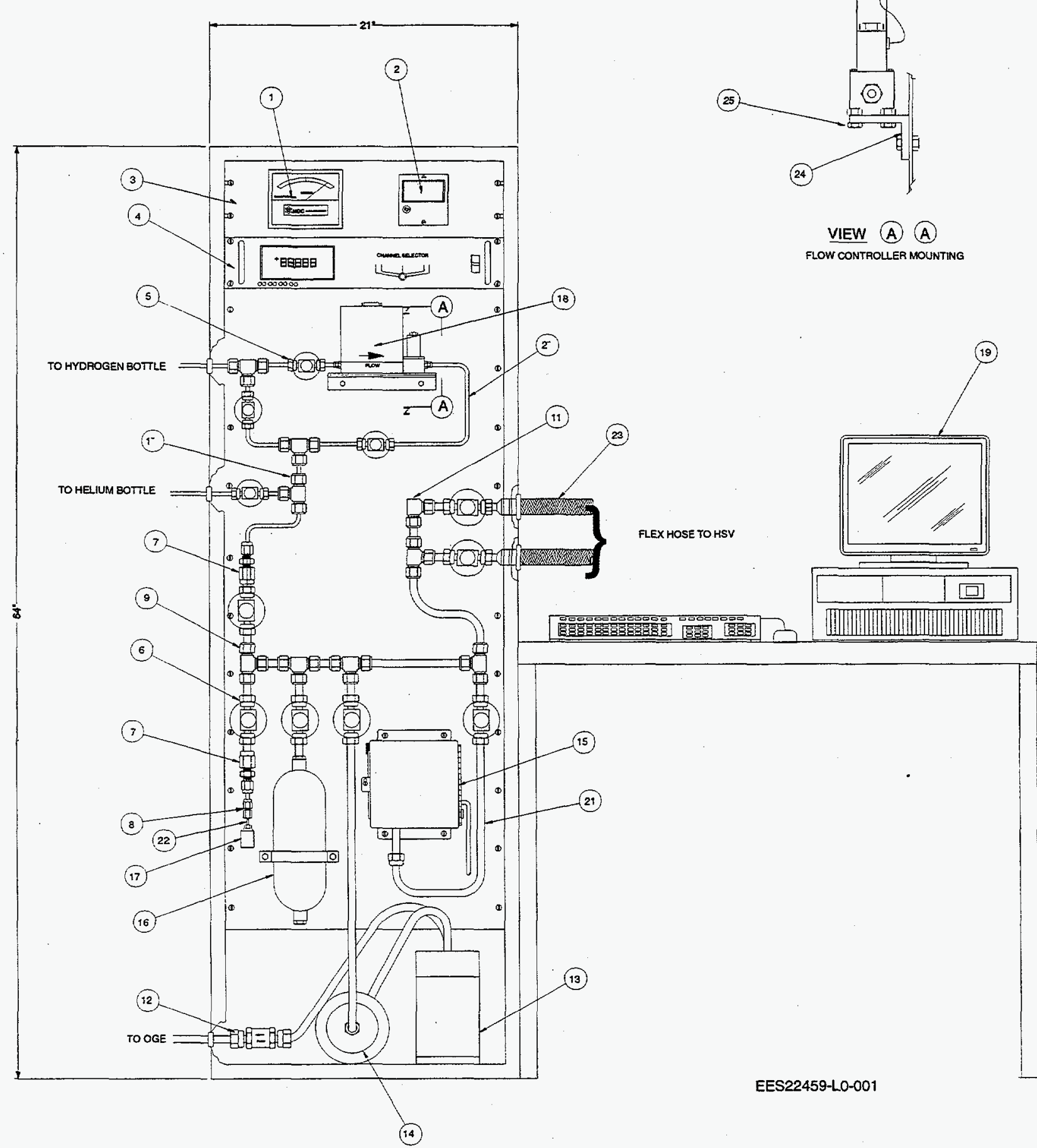

Figure 3. System drawing of gas manifold system. See also Fig. 2. Numbers refer to parts listed in Table I. 


\section{Data Acquisition Diagram}

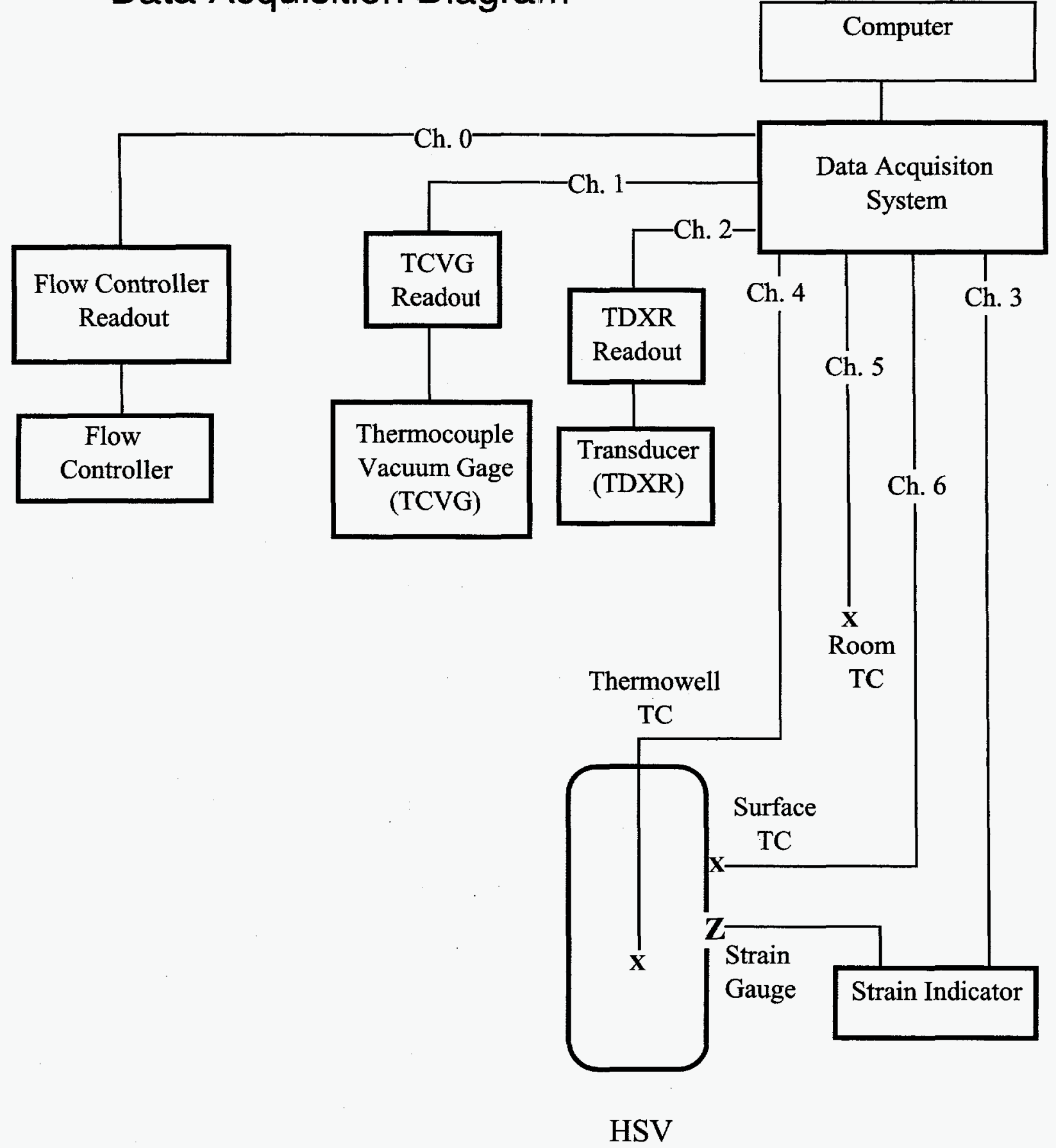

Figure 4. Connection diagram of instrumentation and data acquisition system 


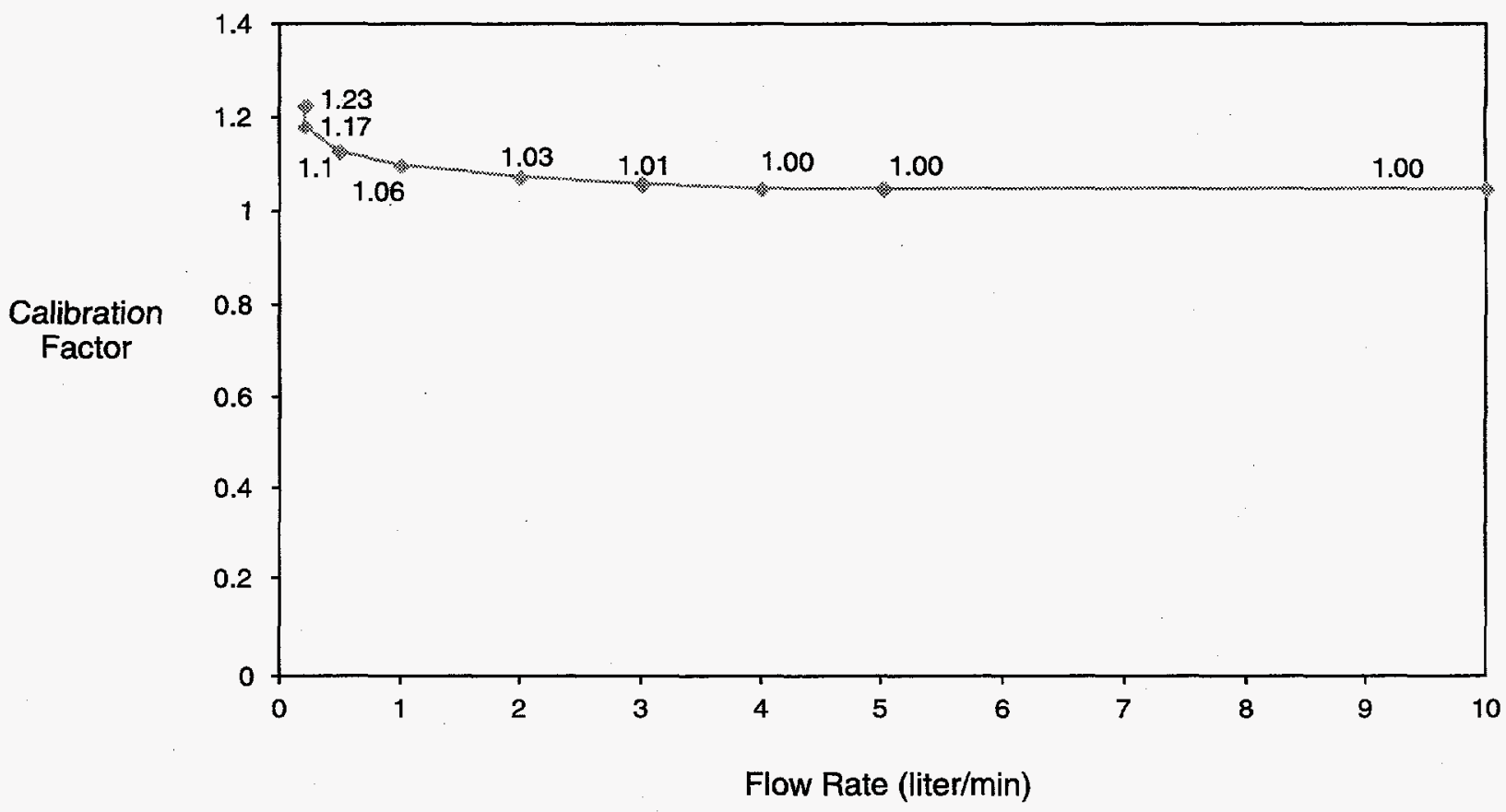

Figure 5. Calibration factor for hydrogen flow through flow controller, as a function of flow rate. Calibration factor is the amount of gas calculated by integrating flow rate output divided by the amount of gas calculated by pressure-volume-temperature (PVT). Calibration factor is 1 for flow $>4$ liter/min; all hydrogen loaded at 5 liter/ min during this study. 


\section{WSRC-TR-97-0187}

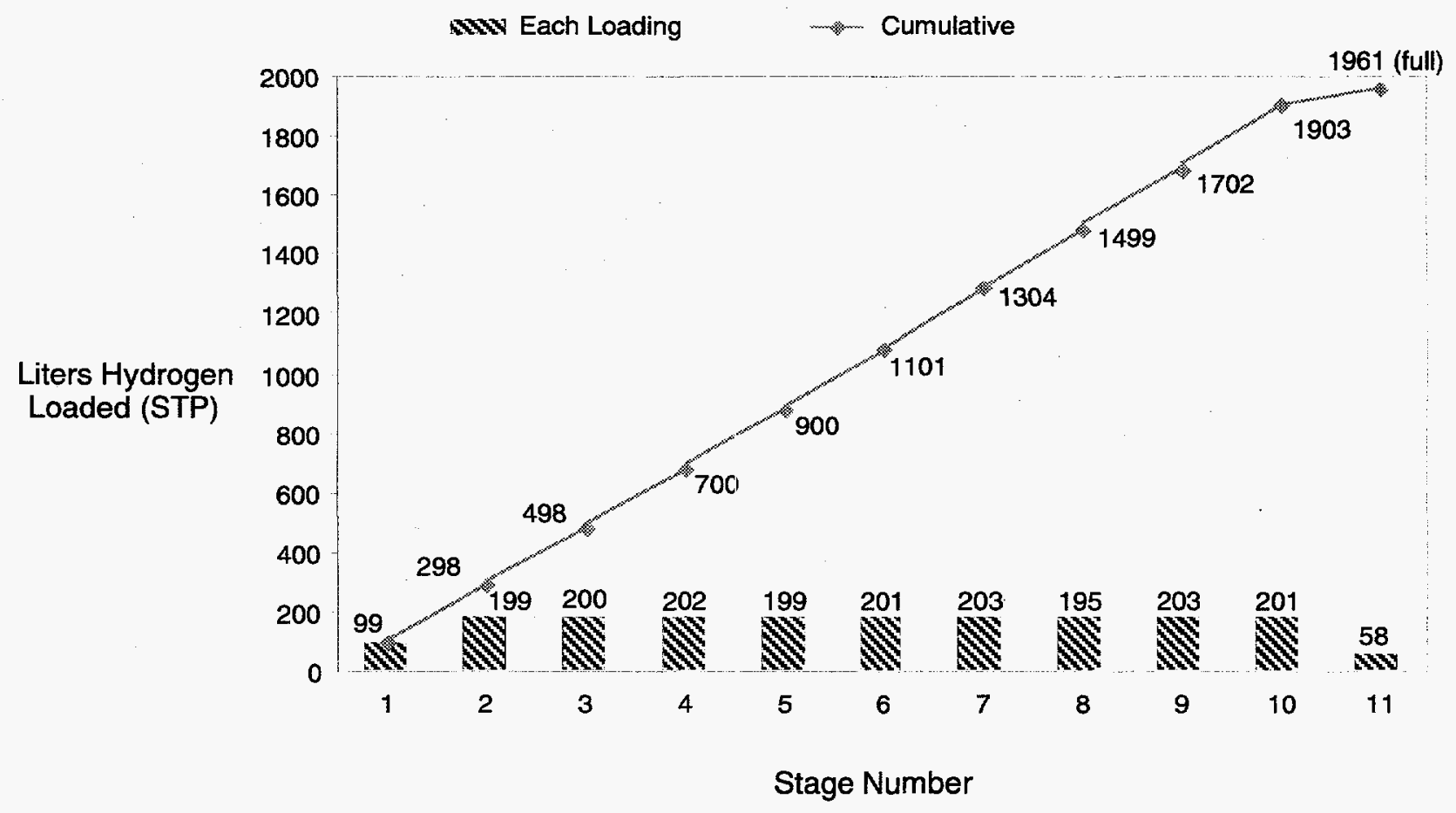

Figure 6. Quantity of hydrogen loaded during each stage and total loaded during this study 
WSRC-TR-97-0187

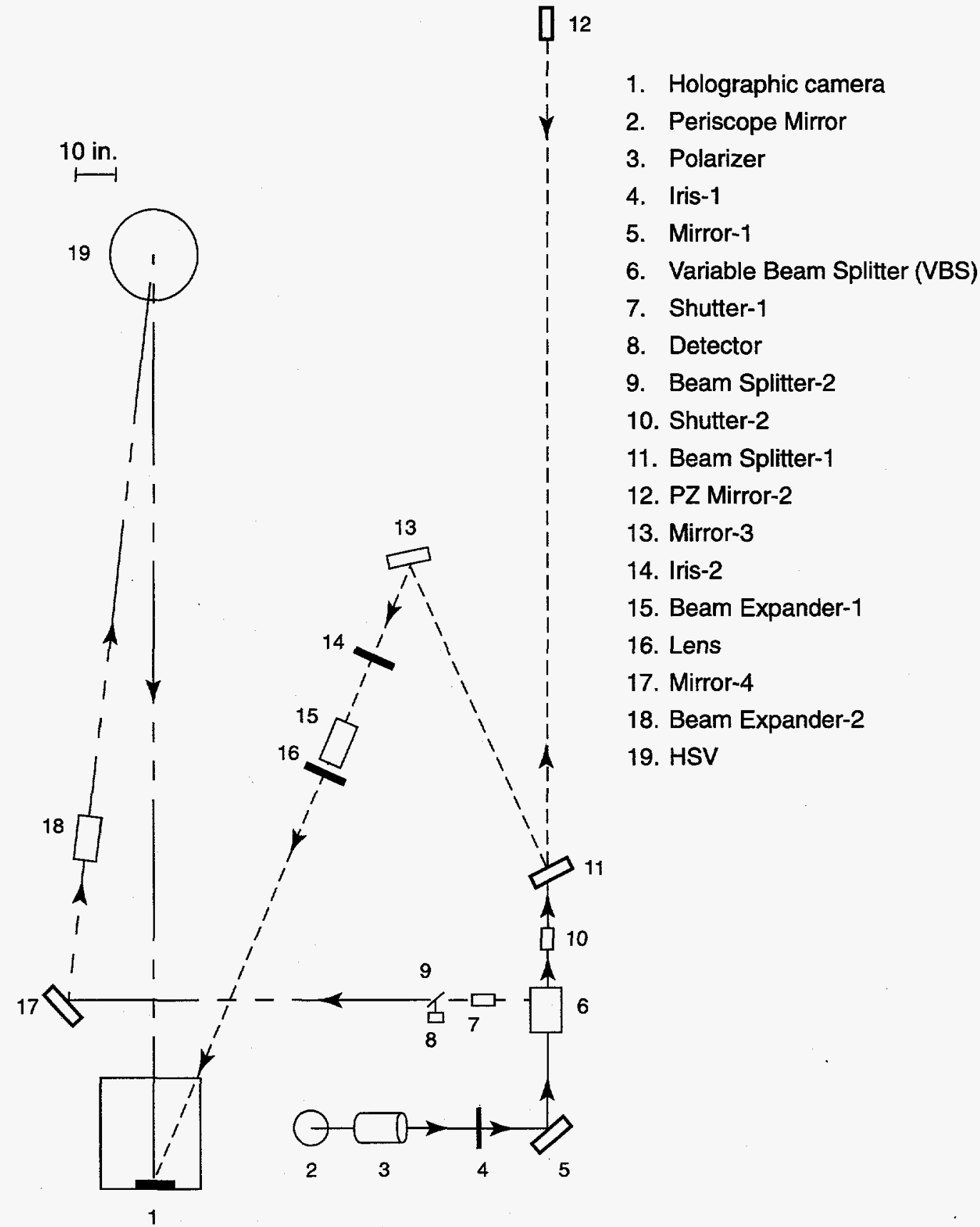

Figure 7. Schematic diagram of holographic interfometry measurement of radial wall displacement. The laser beam emanates from location 2 and is divided into the reference and object beams by Variable Beam Splitter (Item 6). The reference beam propagates through the path defined by Items $10,11,12,13$, and 14 . It is then expanded and collimated (Items 15\&16) and illuminates the holographic plate. The object beam defined by Items 7, 9, 17, and 18 is expanded (Item 18) and illuminates the Hydride Storage Vessel (HSV), which is Item 19. Some of the light scattered from the diffusely reflecting surface of the HSV is intercepted by the holographic plate and interferes with the light from the reference beam to form the hologram. 
WSRC-TR-97-0187

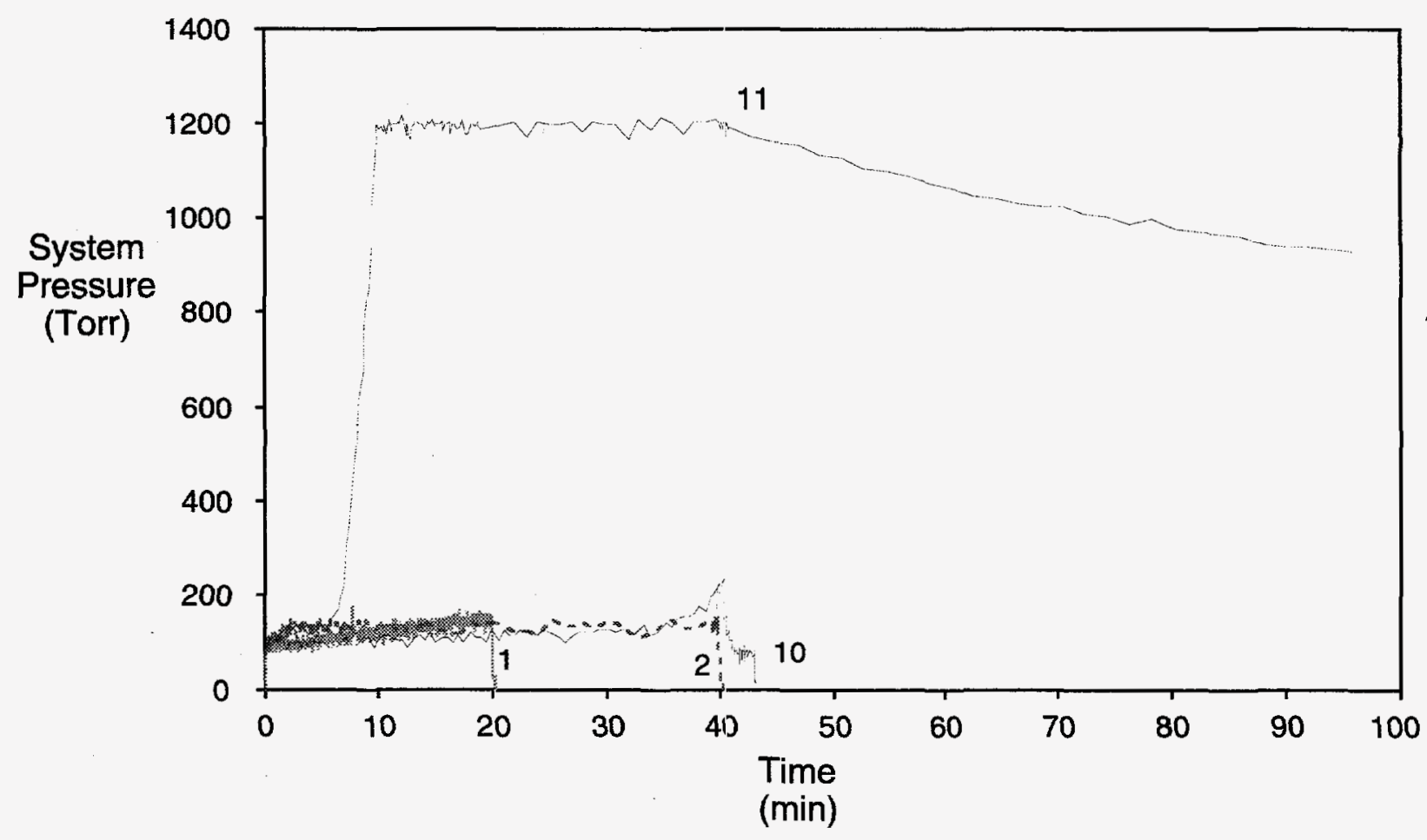

Figure 8. System presssure versus time during loading, stages $1,2,10,11$. Note constant pressure while loading, until near end of loading 10. HSV became saturated during stage 11 , and the system pressure rose to the value set by the hydrogen regulator. Loading during stages 3 through 9 is similar to stage 2 . 


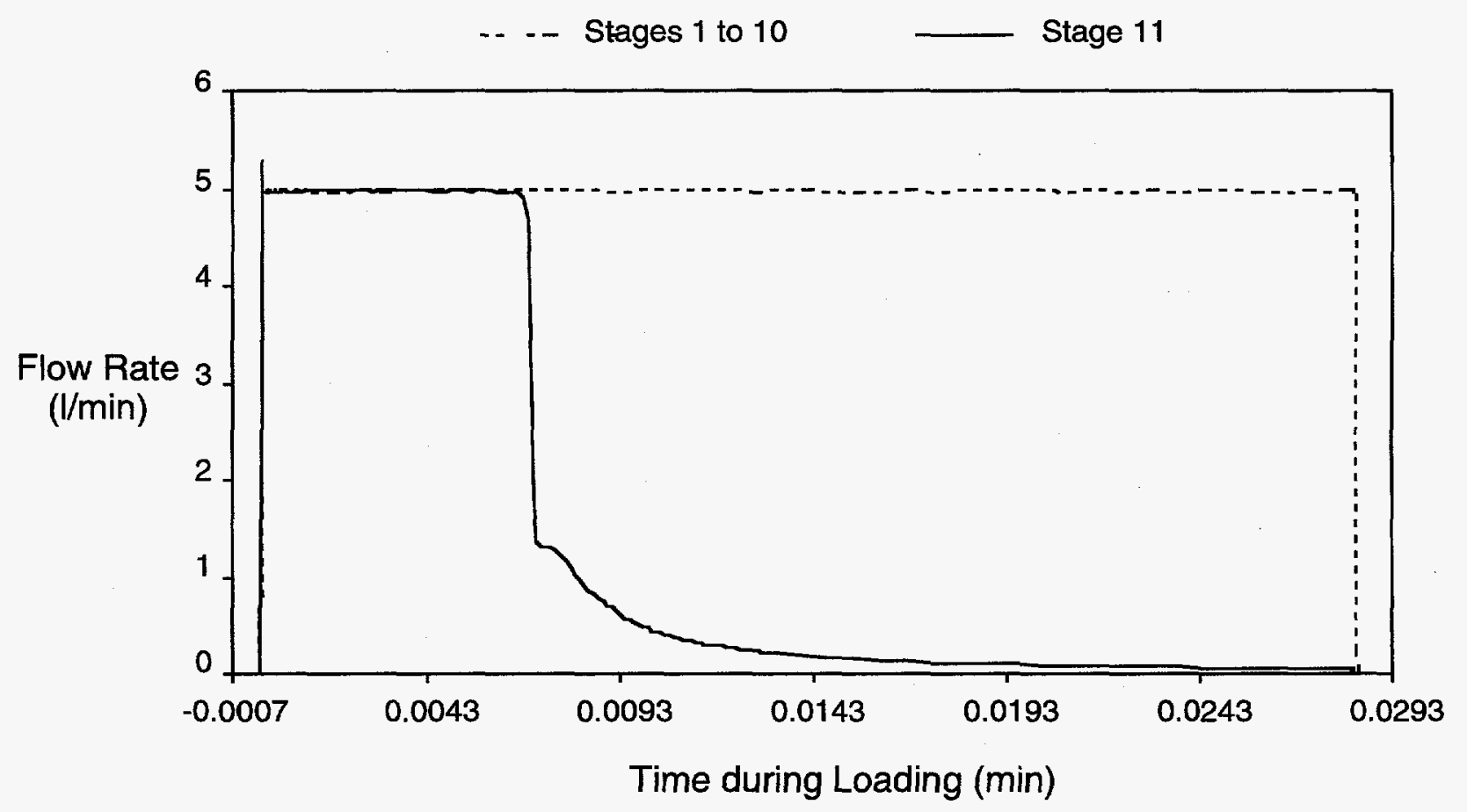

Figure 9. Flow rate versus time for a typical loading (stages 1-10), and for stage 11. Note sudden flow reduction when the bed became full during stage 11 . 
WSRC-TR-97-0187

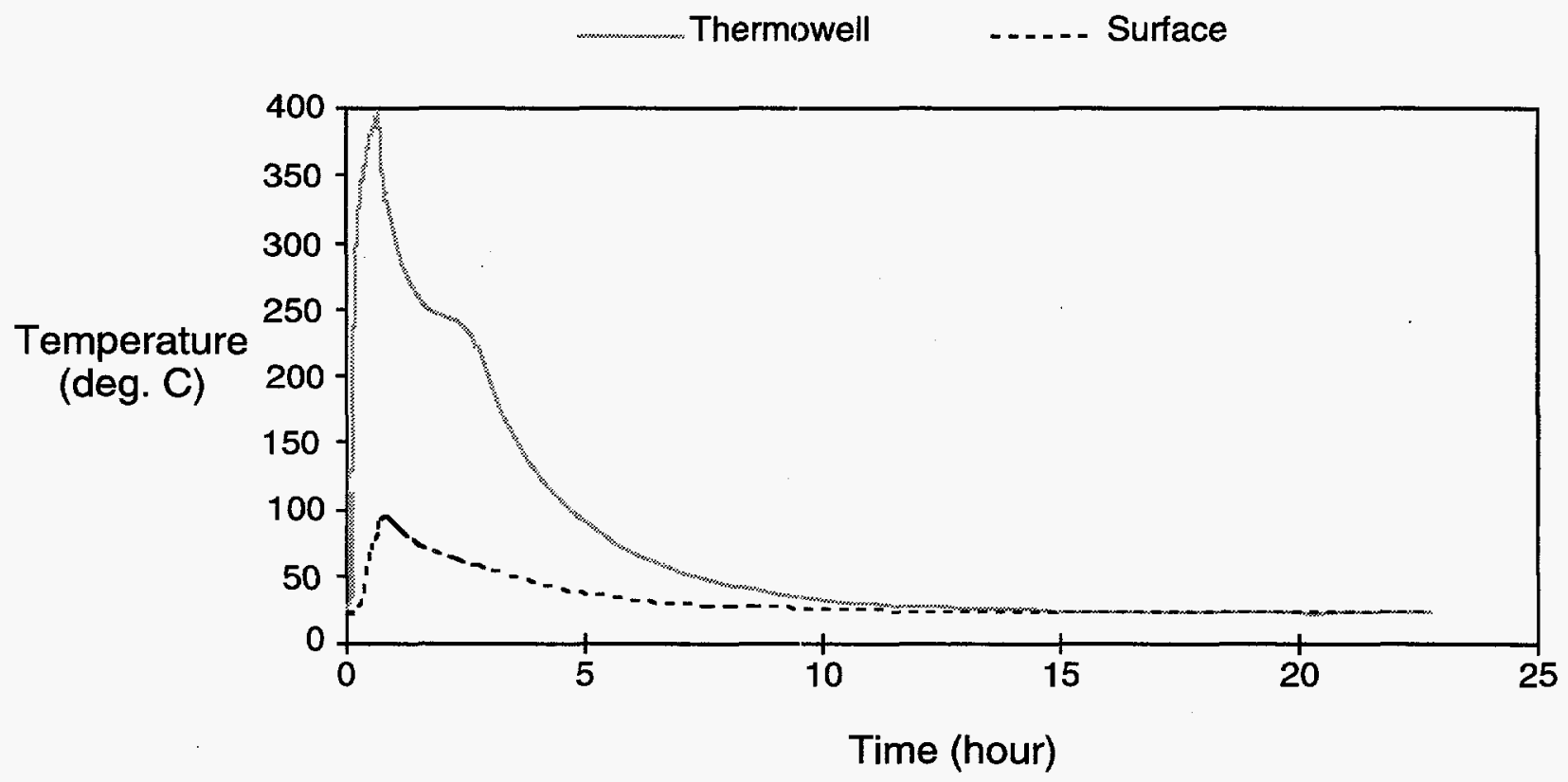

Figure 10. Thermowell and surface temperatures versus time during loading stage 2 (Typical). 24 of 35 
WSRC-TR-97-0187

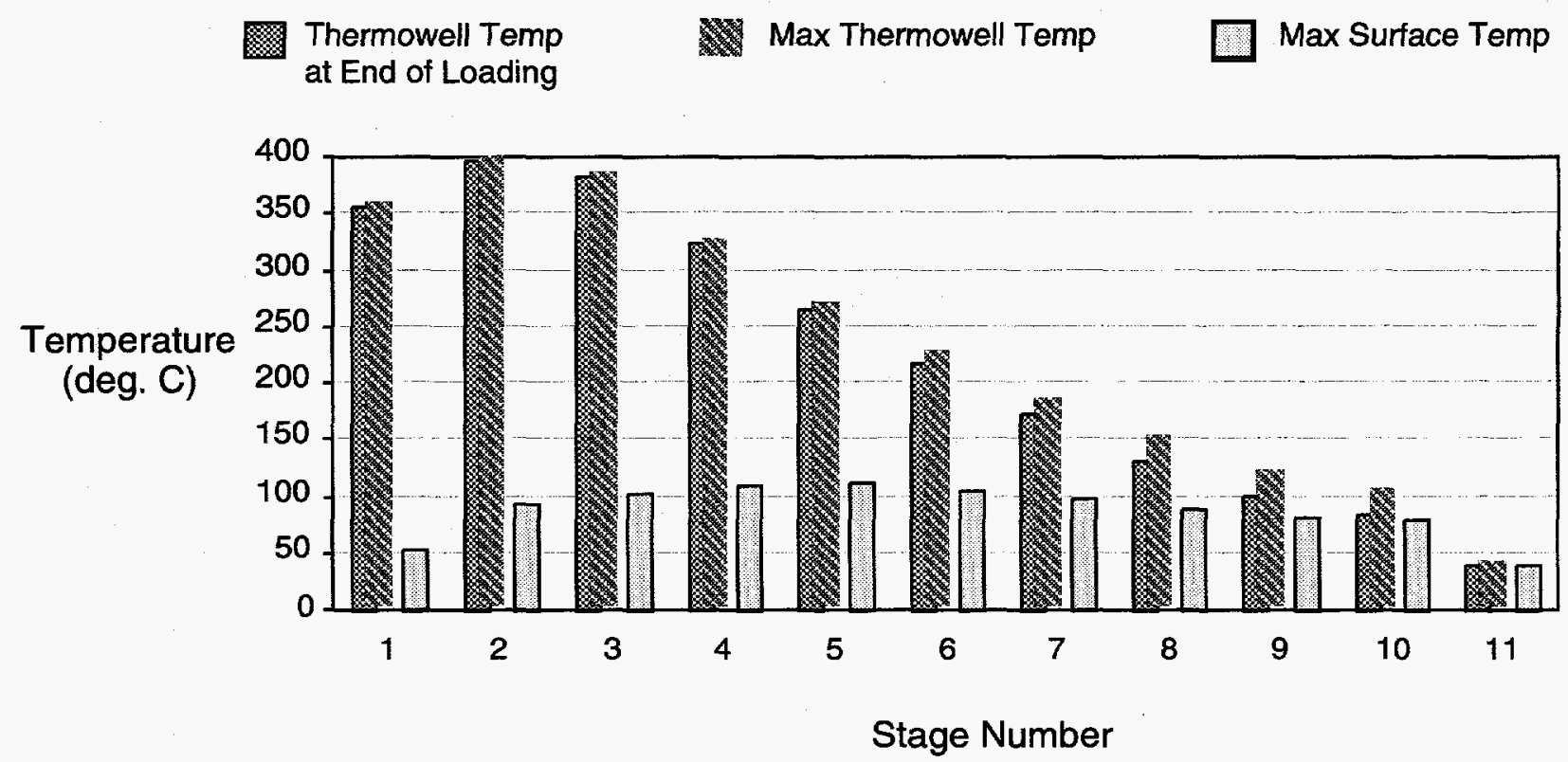

Figure 11. Maximum thermowell temperature, maximum surface temperature, and thermowell temperature at end of loading for each stage. Variation with loading probably reflects changes in location of hydriding at increased bed loadings and cooling by hydrogen flowing through titanium hydride. 
WSRC-TR-97-0187
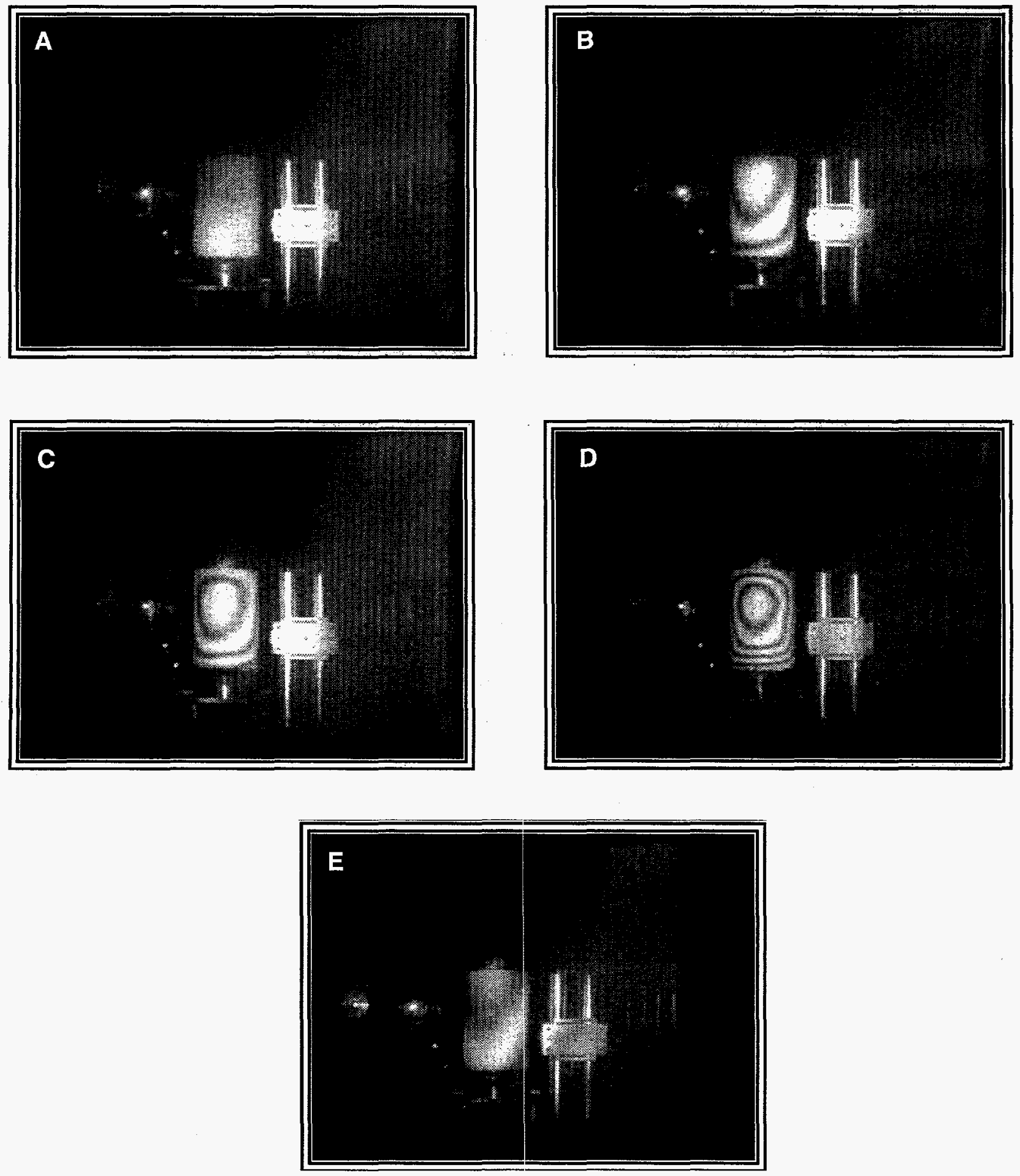

Figure 12. Sequence of interferograms at various helium pressures: a) 10 Torr; b) 413 Torr; c) 740 Torr; d) 1290 Torr; e) 0 Torr. Note increase of number of fringes with increasing pressure. Pressure measured by counting number of vertical fringes at middle of image interferogram and multiplying by a constant. See Fig. 13. 
WSRC-TR-97-0187

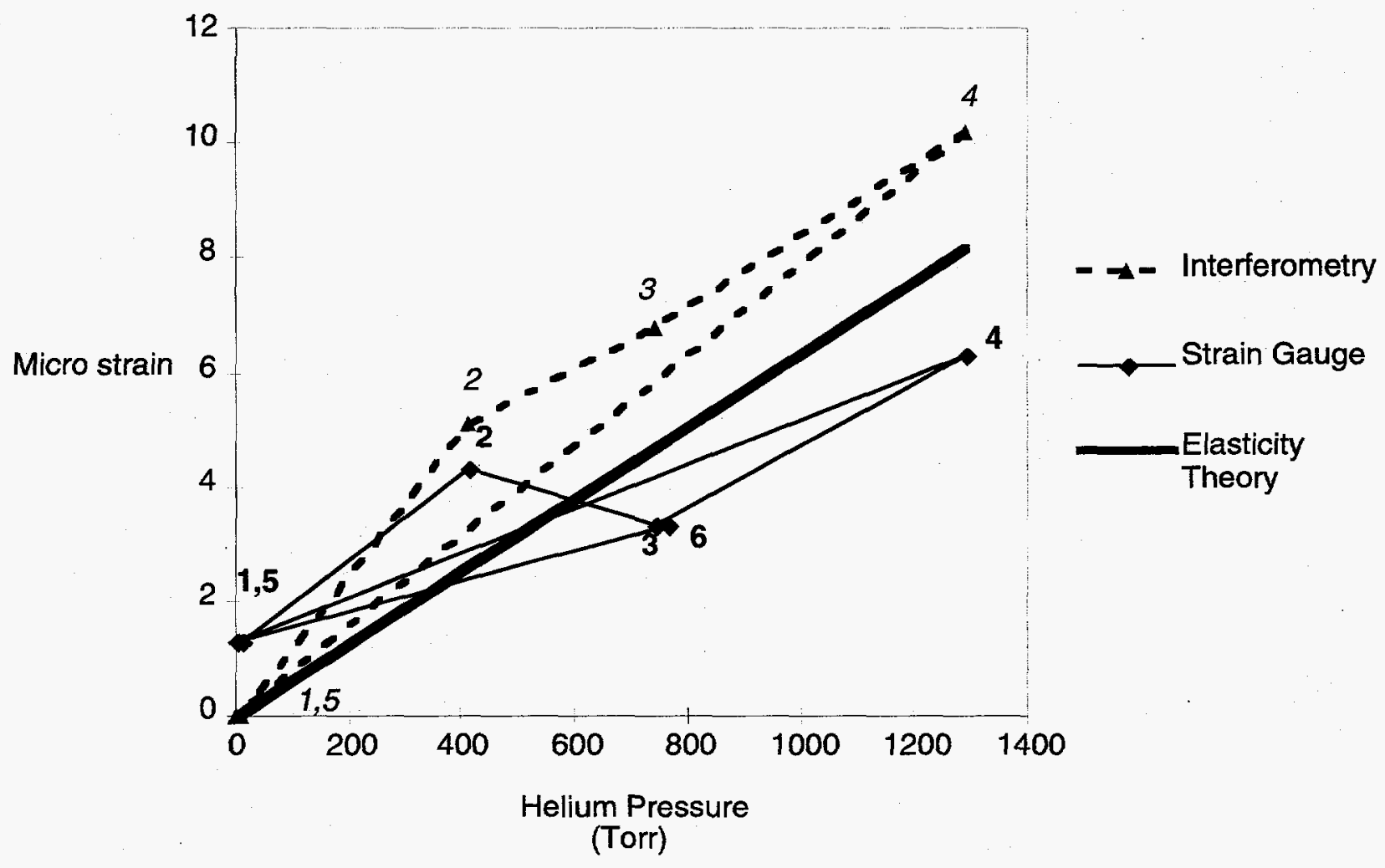

Figure 13. Strain measured by holographic interferometry (Fig. 12), the strain gauge, and that calculated using elasticity theory versus helium pressure in HSV. Numbers refer to the order of pressurization, depressurization, and (strain gauge only) final pressurization. Note excellent agreement between holographic interferometry elasticity theory, and fair agreement of strain gauge. 
WSRC-TR-97-0187

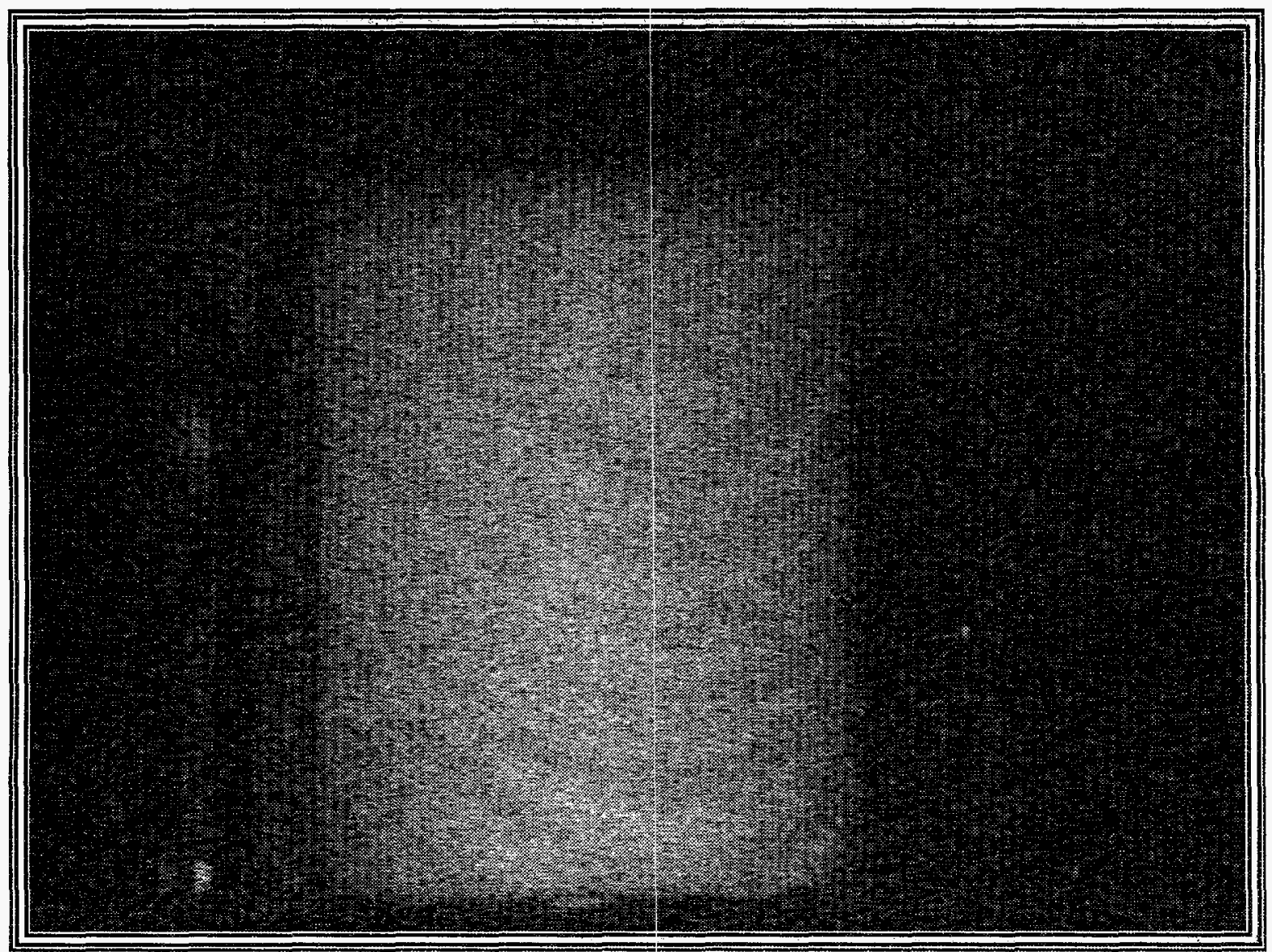

Figure 14. Interferogram made after stage 4. Fringes mainly horizontal and curved. Pattern is indicative of rigid body tilt. 
WSRC-TR-97-0187
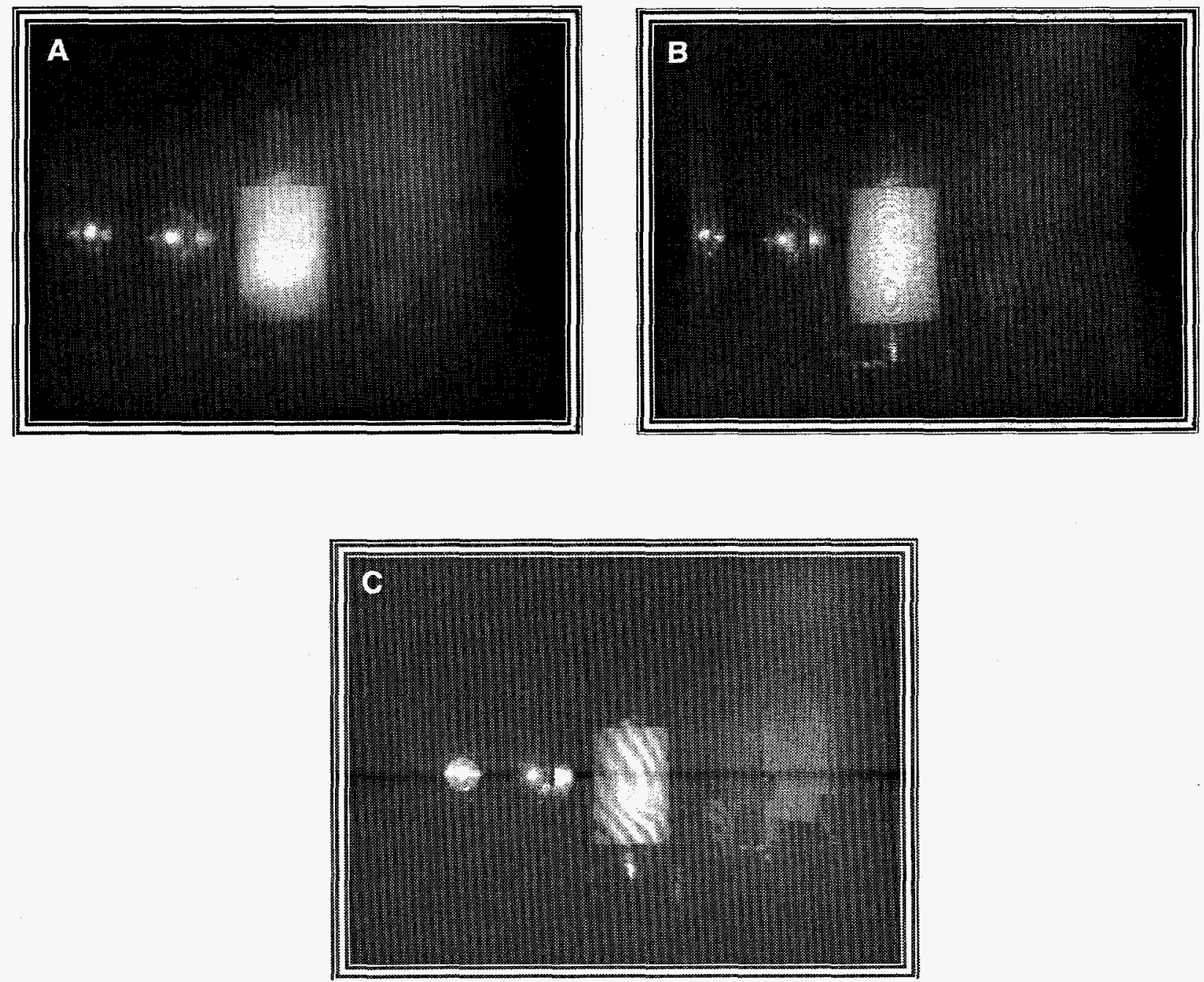

Figure 15. Stage 7 interferometry: (a) reference interferogram (before loading); (b) interferogram after loading, bed still cooling (note complex fringe pattern from thermal expansion); (c) interferogram aftrer bed cooled (fringes mainly vertical, possibly bed expansion). 
WSRC-TR-97-0187

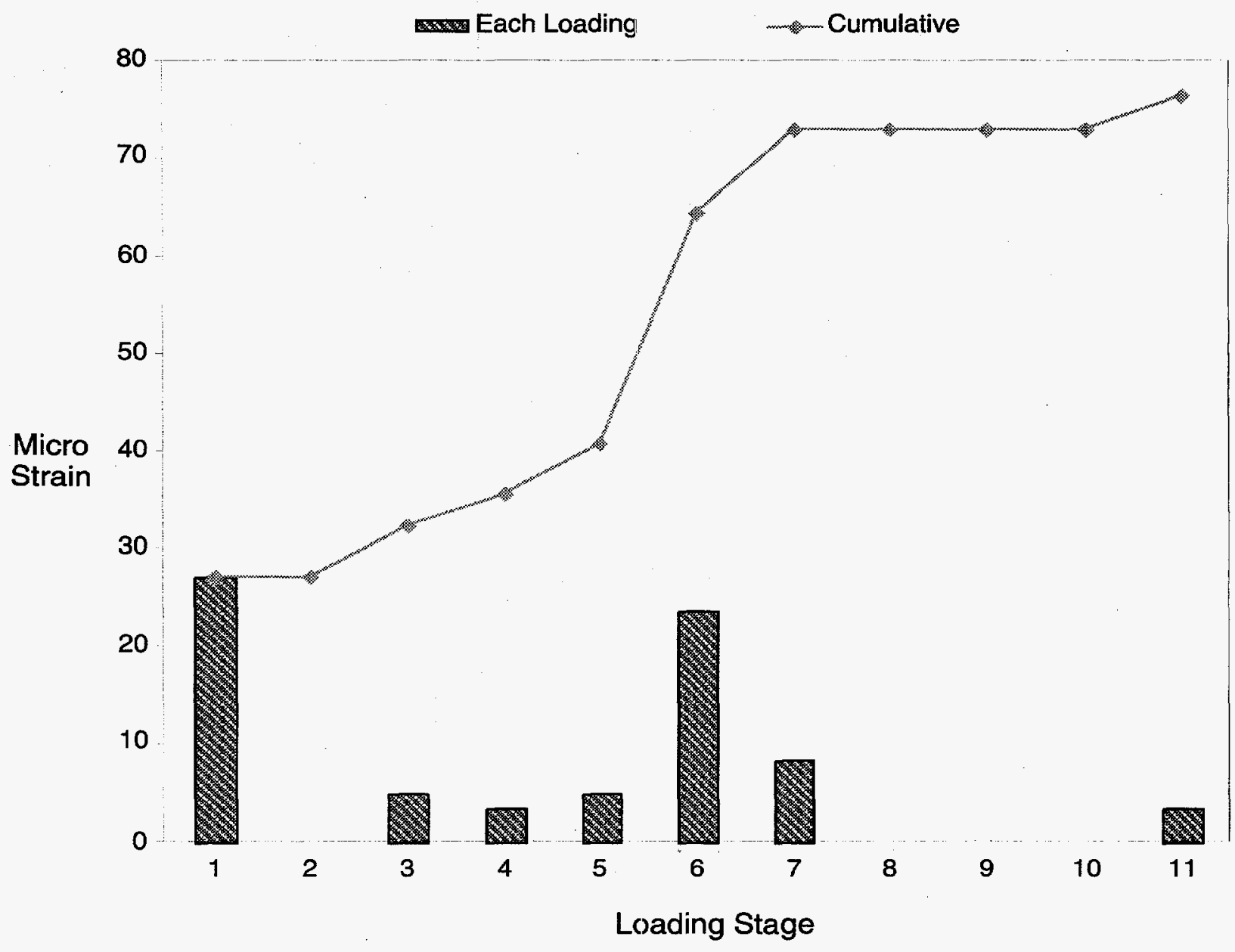

Figure 16. Strain after each HSV loading, calculated by counting the number of vertical fringes in each interferogram and multiplying by appropriate constant. See Table III. 
WSRC-TR-97-0187

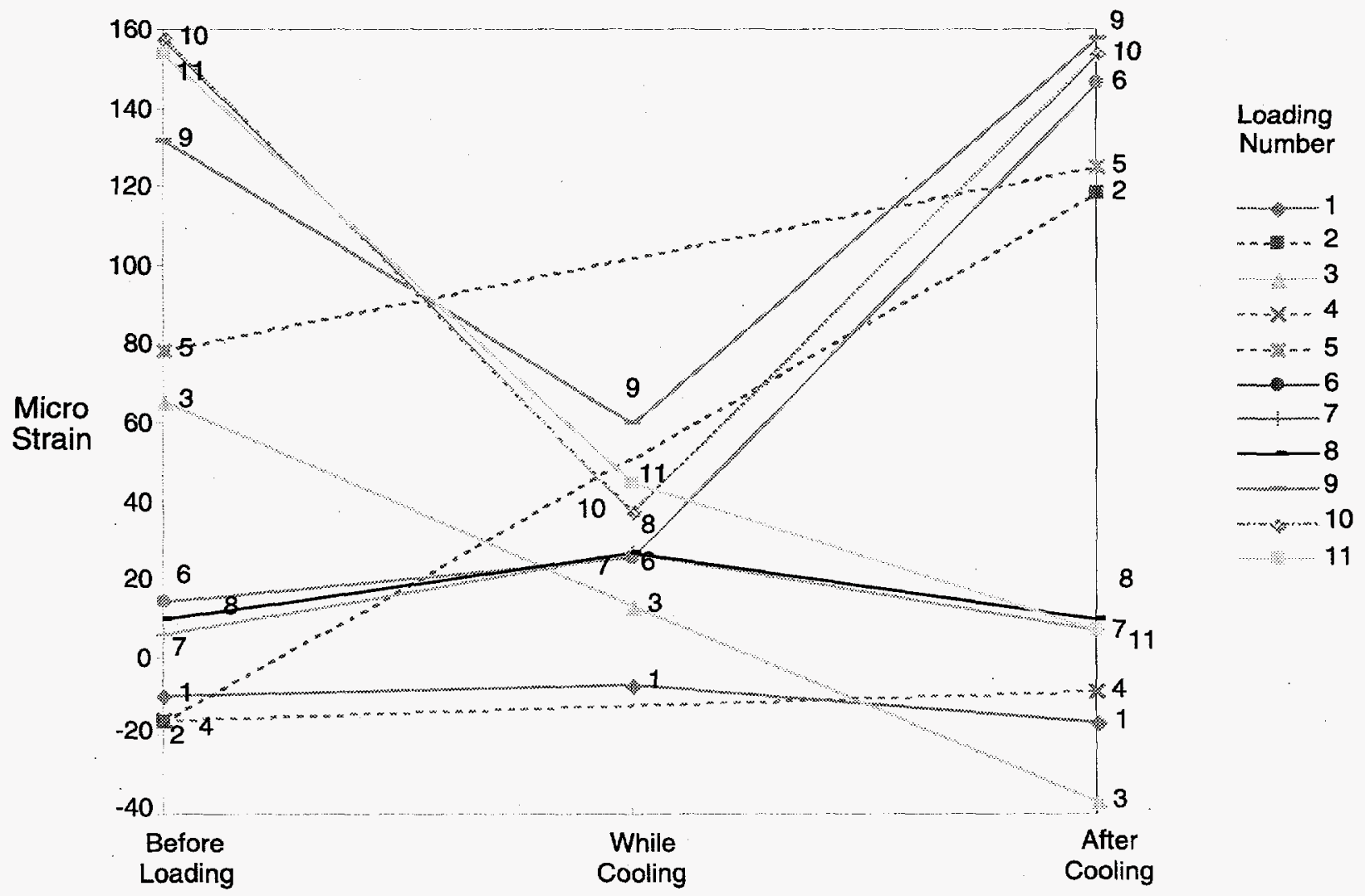

Reading Type

Figure 17. Temperature corrected strain gauge reading before loading, while the HSV was cooling after loading, and after cooling. Numbers in graph refer to loading number to guide the eye. Strain during cooling after stages 2,4 , and 5 was not recorded, signified by dotted line. 


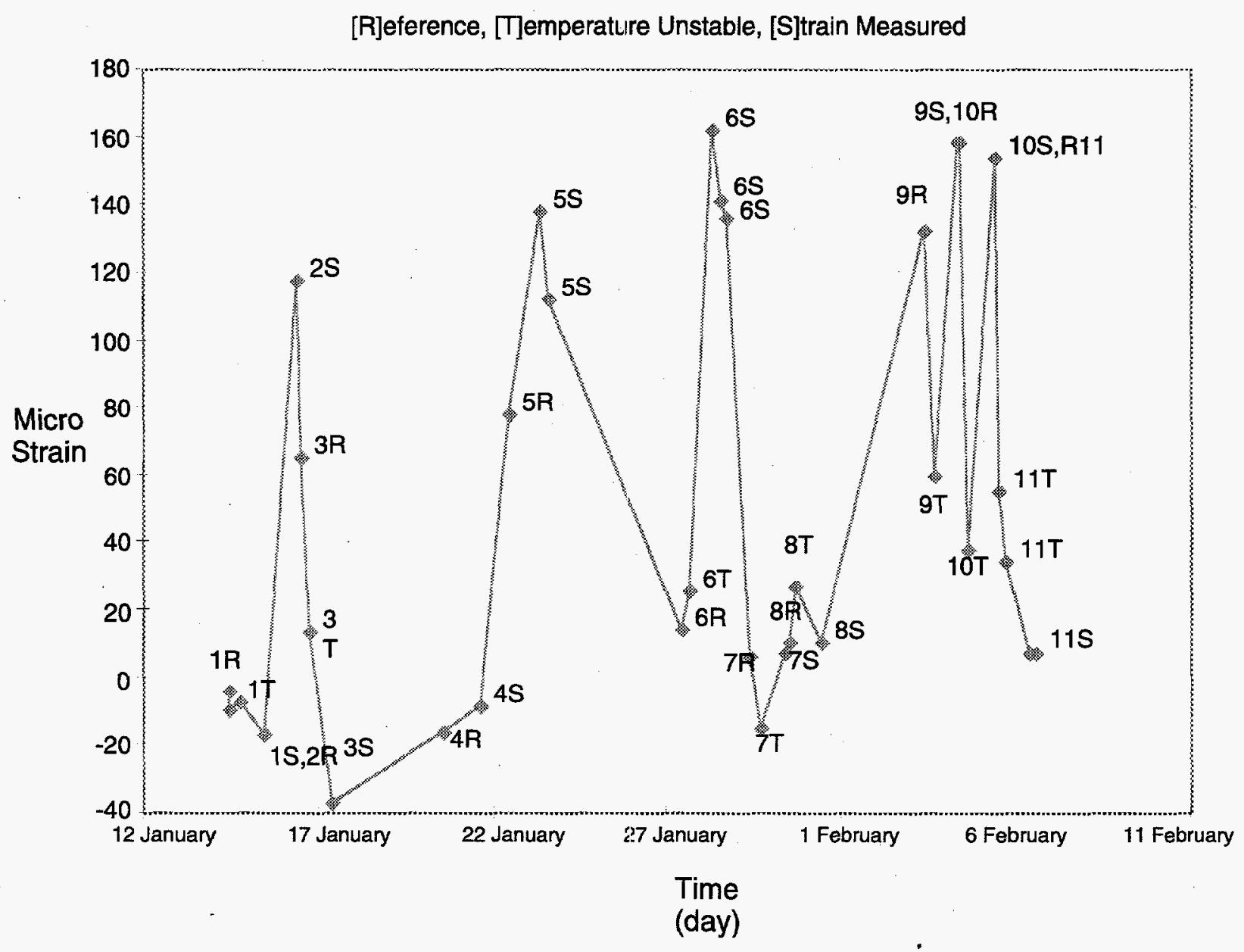

Figure 18. Temperature corrected strain gauge reading as a function of time throughout all hydrogen loading runs. For each point, the load stage number is given, and a letter indicating [R]eference (before loading), [T] emperature unstable (while cooling), and [S ] train measured (after cooling). 
WSRC-TR-97-0187

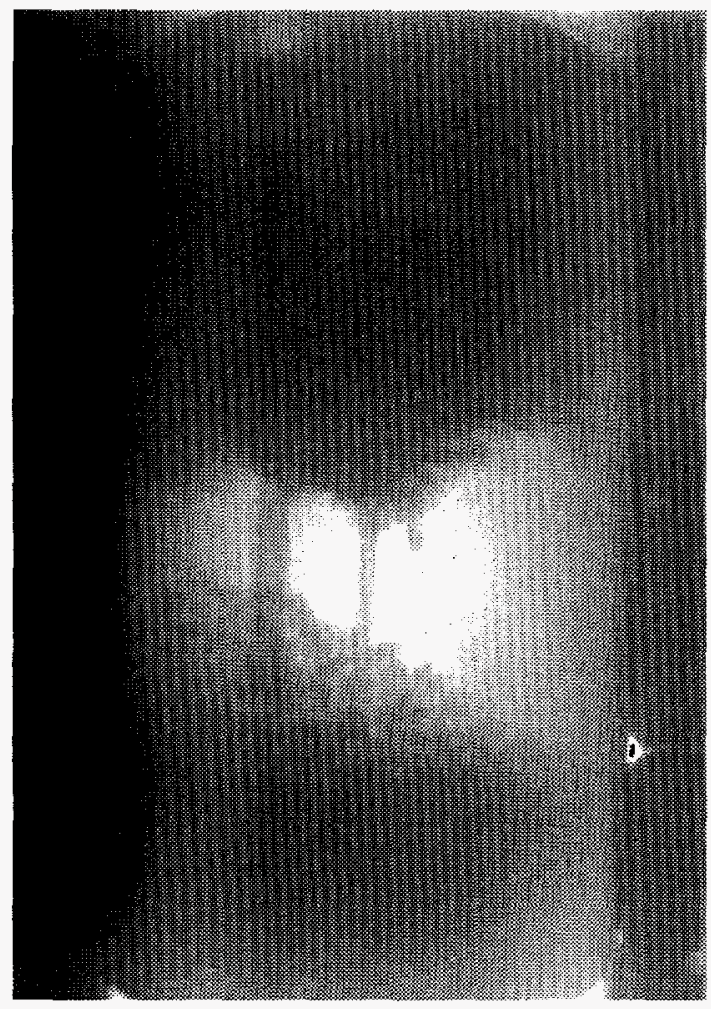

a.

After first loading

$\mathrm{D} / \mathrm{M}-1.83$

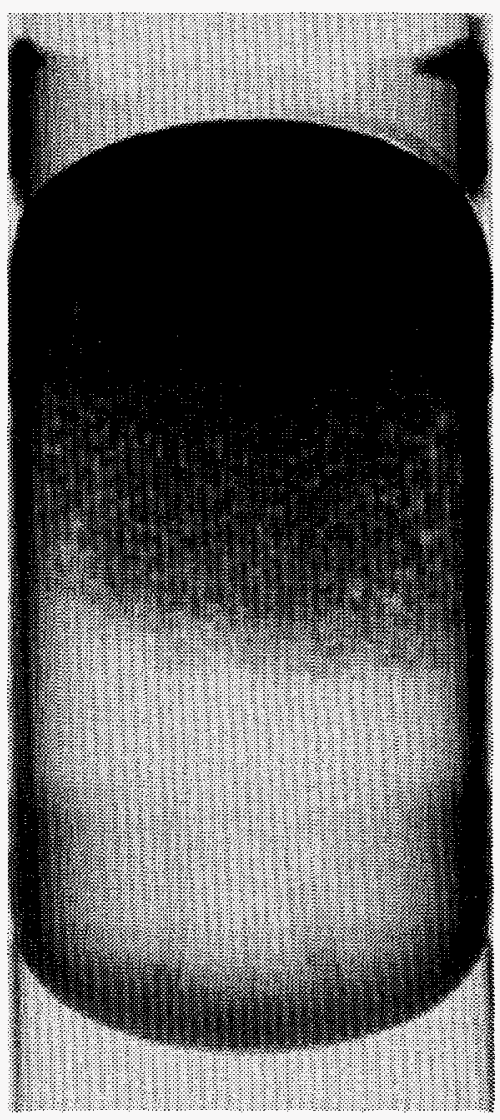

b.

After more than five cycles loading/unloading (including high-flow rate, activation, unloading test)

Figure 19. Radiographs of HSV P-1 revealing partial and full agglomeration during testing before this study. 
WSRC-TR-97-0187

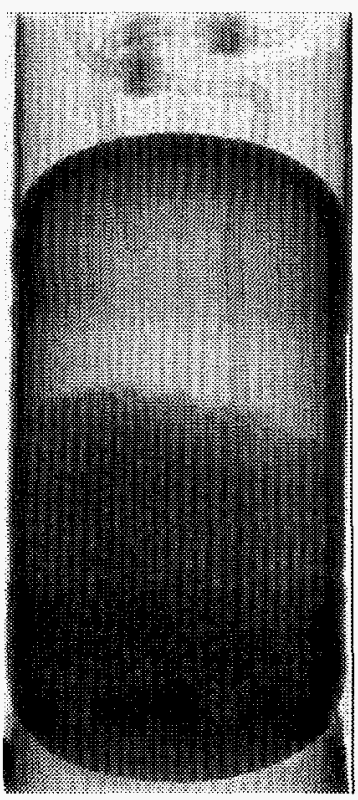

a.

Normal

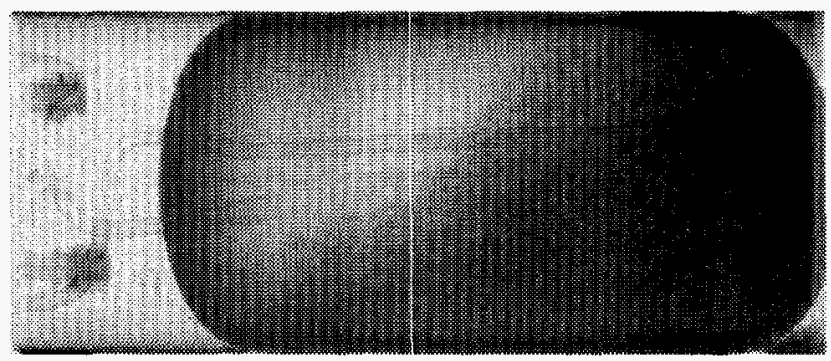

b. Side

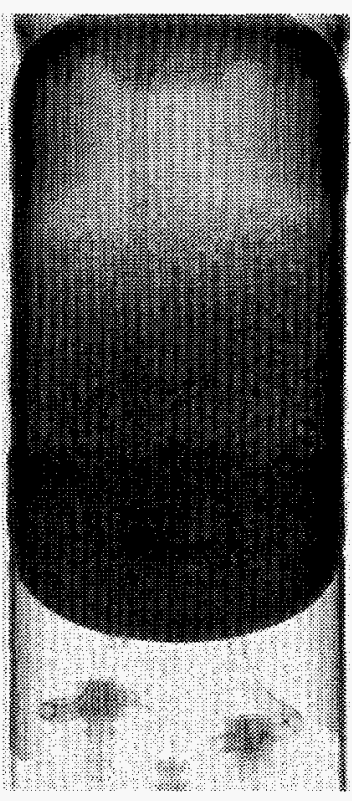

c. Inverted

Figure 20. Radiographs of HSV P-2 revealing that titanium hydride flows in fully loaded bed. 
WSRC-TR-97-0187

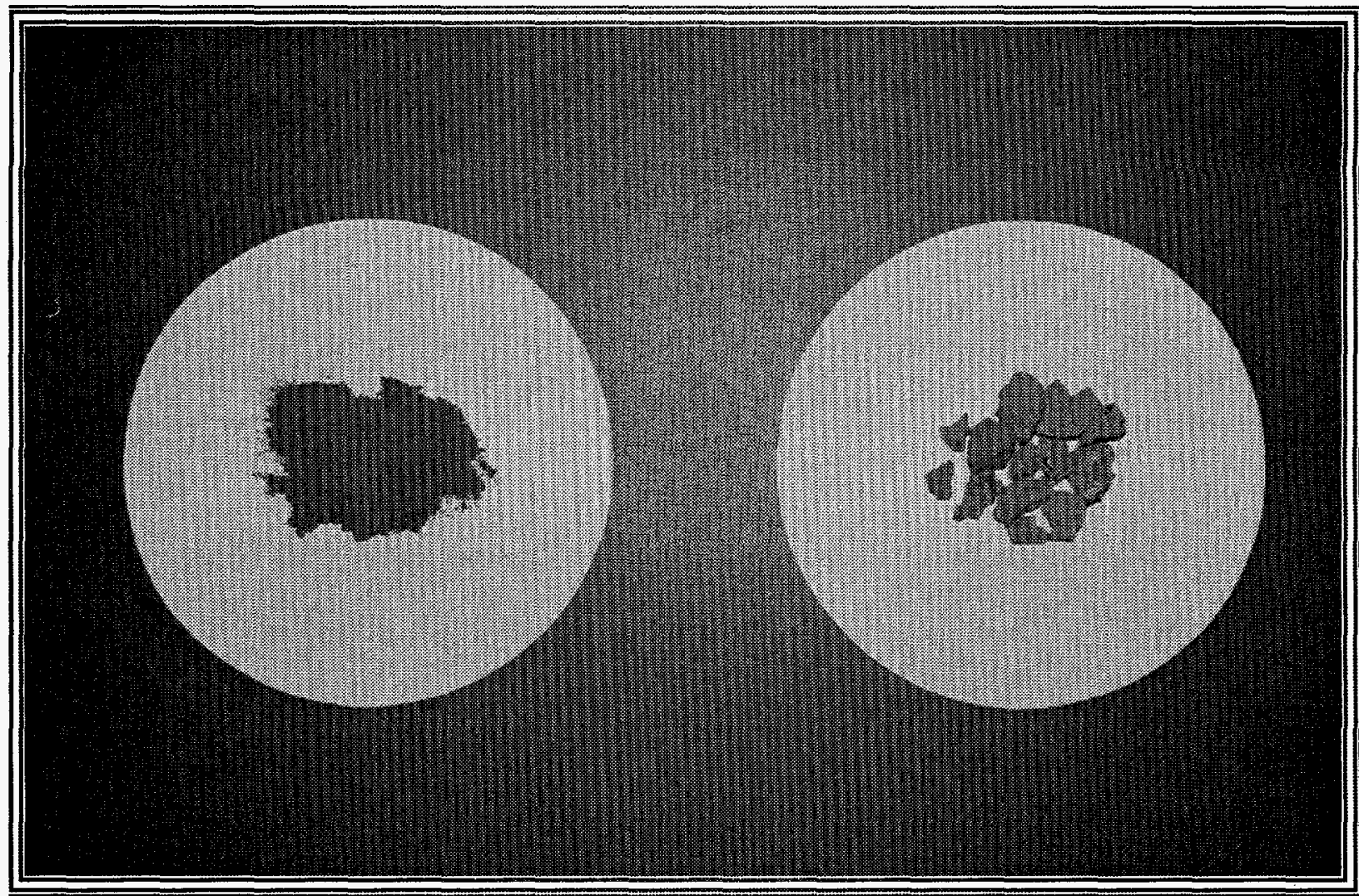

$\mathrm{LaNi}_{4.7} \mathrm{Al}_{0.3}$

$\mathrm{Ti}$

Figure 21. Photograph of samples of $\mathrm{LaNi}_{4.7} \mathrm{~A}_{0.3}$ (used in storage beds) and titanium (used in HSV). Note fine powder morphology of $\mathrm{LaNi}_{4.7} \mathrm{Al}_{0.3}$, and large chunk morphology for titanium. (white background disks $31 / 2$ inches diameter) 